University of Massachusetts Amherst

ScholarWorks@UMass Amherst

Civil and Environmental Engineering Faculty

Publication Series

2021

Strength-dilatancy and critical state behaviours of binary

mixtures of graded sands influenced by particle size ratio and

fines content

Yuksel Yilmaz

Yibing Deng

Ching S. Chang

Aydin Gokce 


\title{
Strength-dilatancy and critical state behaviours of binary mixtures of graded sands influenced by particle size ratio and fines content
}

\author{
YUKSEL YILMAZ*, YIBING DENG $\dagger$, CHING S. CHANG $\$$ and AYDIN GOKCE§
}

\begin{abstract}
Binary granular soil mixtures, as common heterogeneous soils, are ubiquitous in nature and man-made deposits. Fines content and particle size ratio are two important gradation parameters for a binary mixture, which have potential influences on mechanical behaviours. However, experimental studies on drained shear behaviour considering the whole range of fines content and different particle size ratios are scarce in the literature. For this purpose, a series of drained triaxial compression tests was performed on dense binary silica sand mixtures with four different particle size ratios to investigate systematically the effects of fines content and particle size ratio on the drained shear behaviours. Based on these tests, the strength-dilation behaviour and critical state behaviour were examined. It was observed that both fines content and particle size ratio have significant influence on the stress-strain response, the critical state void ratio, the critical state friction angle, the maximum dilation angle, the peak friction angle and the stress-dilatancy relation. The underlying mechanism for the effects of fines content and particle size ratio was discussed from the perspective of the kinematic movements at particle level.
\end{abstract}

KEYWORDS: deformation; laboratory tests; particle-scale behaviour; sands; shear strength

\section{INTRODUCTION}

Heterogeneous soils are ubiquitous in nature and man-made deposits. These soils are generally composed of a binary mixture of large particles and small particles, such as gravelsand mixtures and sand-silt mixtures, which are commonly encountered in dams, fills, fault zones and landslides. The mechanical behaviours of binary soil mixtures have been found to be very different from that of uniform soil (Salgado et al., 2000; Carraro et al., 2009; Chang \& Phantachang, 2016; Derkaoui et al., 2016; Jehring \& Bareither, 2016).

Fines content and particle size ratio are two important gradation parameters for a binary mixture, which distinguish mixtures from uniform soils. Thus, it is important to understand the effects of fines content and particle size ratio on the mechanical behaviour of a binary soil mixture.

Many efforts have been made to study the behaviour of binary soil mixtures. The effects of fines content on critical void ratio have been studied using the experimental results of many investigators (e.g. Zlatović \& Ishihara, 1995; Thevanayagam et al., 2002; Naeini \& Baziar, 2004; Yang, 2004; Papadopoulou \& Tika, 2008; Carrera et al., 2011; Dash \& Sitharam, 2011; Kwa \& Airey, 2016). All these results show significant effects of fines content on critical state void ratio, which decreases as fine content increases from zero to about $30 \%$. Then, as the fines content continues to increase, the void ratio increases. This trend is very useful for the evaluation of the engineering properties of silty sands using the critical state soil mechanics framework.

The effect of fines content on dilatancy for silty sands is usually studied by drained triaxial tests. However, there are

Manuscript received 9 September 2020; revised manuscript accepted 18 May 2021.

* Gazi University, Ankara, Turkey (Orcid:0000-0001-7630-7357).

$\uparrow$ University of Massachusetts Amherst, Amherst, MA, USA (Orcid:0000-0001-5343-1988).

+ University of Massachusetts Amherst, Amherst, MA, USA (Orcid:0000-0002-3595-5099).

$\S$ Gazi University, Ankara, Turkey (Orcid:0000-0002-1611-2168). limited studies in this area (Salgado et al., 2000; Carraro et al., 2009; Xiao et al., 2017; Patil et al., 2018). Also, in these studies, the fines contents were less than $30 \%$. Among these studies, some investigators stated that the Bolton's dilatancy equation proposed for clean sand could still be used for silty sands (Xiao et al., 2017) with the same parameter $b: b=$ $\left(\phi_{\mathrm{p}}-\phi_{\mathrm{cv}}\right) / \psi_{\mathrm{p}}$, where $\phi_{\mathrm{p}}, \phi_{\mathrm{cv}}$ and $\psi_{\mathrm{p}}$ are the peak friction angle, critical state friction angle and maximum dilation angle, respectively. $b$ is a dilatancy parameter of 0.436 for Fujian sand with non-plastic fines. This statement needs to be verified for the case of higher fines content (i.e. greater than $30 \%$ ).

The effects of fines content on the critical state friction angle have been studied by both drained and undrained triaxial tests. Some investigators have found that the critical state friction angle varies with fines content (Salgado et al., 2000; Murthy et al., 2007; Xiao et al., 2017), while others have found that the critical state friction angle is independent of fines content (Bouckovalas et al., 2003; Ni et al., 2004; Rahman et al., 2014).

Based on these investigations, fines content has been found to have a significant influence on the soil behaviours associated with void ratio, such as maximum and minimum densities, critical state line, normal compression line and so on. For each soil behaviour, investigations have indicated the existence of a transitional or threshold fines content, which is considered to be the boundary between behaviour dominated by the coarser particles and behaviour dominated by the finer particles in binary mixtures (Thevanayagam et al., 2002; Yang et al., 2006; Chang \& Meidani, 2013; Zuo \& Baudet, 2015). The concept of transitional fines content has been broadly accepted in soil mechanics. The transitional fines content is different for different soil behaviour, and usually varies between 20 and $50 \%$, as discussed by Zuo \& Baudet (2015). The existence of a transitional fines content, however, has not been discussed in the literature for strength-dilatancy behaviour, and this needs to be investigated.

Besides fines content, the particle size ratio is also an important factor for a binary mixture. However, until now, very few studies have been available in the literature that address the effect of particle size ratio on critical state behaviour and strength-dilatancy behaviour. Although there 
are abundant drained triaxial test results on silty sands in the literature, these test results cannot be used to evaluate the effect of particle size ratio because the particle size ratio cannot be isolated from other factors. As far as the current authors are aware, there have been only a few studies on particle size ratio using discrete-element simulations (Ueda et al., 2011; Zhou et al., 2016; Zhu et al., 2020). In the literature, however, there have been no attempts made using real soil mixtures or glass beads mixtures to study the effect of particle size ratio on critical state behaviour and stressdilatancy behaviour.

The main objective of this work is to investigate the effects of fines content and particle size ratio on the critical state behaviour and strength-dilatancy behaviour of binary granular soil mixtures. For this purpose, a series of drained triaxial compression tests at a constant confining stress $(200 \mathrm{kPa})$ was conducted on dense binary silica sand mixtures. These binary mixtures were made up of five size classes of sand particles with various fines contents so that the factor of particle size ratio could be isolated. This paper is organised as follows. The testing programme and test results are first presented. Then the test results are analysed to observe the effects of fines content and particle size ratio on the critical state and the strength-dilatancy characteristics of the mixed graded material. The observed patterns are discussed and the underlying mechanism for the influences of fines content and particle size ratio on drained shear behaviour is discussed.

\section{TESTING PROGRAMME}

\section{Testing material}

Pasabahce silica sand (herein referred to as silica sand) was selected to use in this experimental study. This silica sand is formed as a result of disintegration of magmatic metamorphic rocks that are rich in quartz. Fluvial transportation brought this material to deposit in Istanbul, Turkey. By sieving the silica sand, five graded uniform silica sands were obtained and are used in this experimental study - namely, \#16-\#18, \#30-\#50, \#50-\#80, \#100-\#120 and \#120-\#200, each range showing the upper and lower sieve numbers. The particle size and specific gravity of the samples (obtained using ASTM D854-14 (ASTM, 2014)) are listed in Table 1. A qualitative look at the shape and surface texture of the individual sand grains were determined using the method of two-dimensional microscopy. Fig. 1 shows a series of micrographs of some grains from the silica sands used in this study. The sand grains are mostly sub-angular. Based on these micrographs, the roundness $\left(R_{\mathrm{W}}\right)$ for each uniform sand was calculated using its definition as proposed by Wadell (1935) and listed in Table 1 . The minimum void ratio $e_{\min }$ (maximum index density) and the maximum void ratio $e_{\max }$ (minimum index density) of each uniform silica sand were determined according to method 2A of ASTM D4253 (ASTM, 2006a) and method B of ASTM D4254 (ASTM, 2006b), respectively. The minimum and the maximum void ratios of samples are presented in Table 1.

To study the effects of fines content and particle size ratio, four series of binary mixtures with four different particle size ratios were prepared by mixing \#16-\#18 uniform sand with one of the other four uniform sands. Herein, the \#16-\#18 sand is referred to as 'coarse' particles and the other four sands of smaller size are referred to as 'fine' particles. For each particle size ratio, the series of binary mixtures was prepared with fines content $f_{\mathrm{c}}=0 \cdot 1,0 \cdot 2,0 \cdot 3,0 \cdot 5,0 \cdot 7$. Fines content is defined in this study as the ratio of the mass of the small-particle sand to the total mass of the binary mixture. Particle size ratio is the ratio of the large particle size to the

Table 1. Properties of the uniform silica sands of five different particle sizes

\begin{tabular}{|c|c|c|c|c|c|c|}
\hline Uniform sand* & Notes $^{\dagger}$ & $d_{50}: \mathrm{mm}$ & Roundness & $G_{\mathrm{s}}$ & $e_{\max }$ & $e_{\min }$ \\
\hline \#16-\#18 & Medium sand & $1 \cdot 086$ & $0 \cdot 36$ & $2 \cdot 624$ & 0.901 & 0.632 \\
\hline \#30-\#50 & Medium/Fine sand & $0 \cdot 424$ & $0 \cdot 26$ & $2 \cdot 640$ & 0.999 & 0.698 \\
\hline \#50-\#80 & Fine sand & $0 \cdot 232$ & $0 \cdot 17$ & $2 \cdot 646$ & $1 \cdot 102$ & 0.786 \\
\hline \#100-\#120 & Fine sand & $0 \cdot 137$ & $0 \cdot 18$ & $2 \cdot 652$ & $1 \cdot 108$ & 0.778 \\
\hline \#120-\#200 & Fine sand & $0 \cdot 096$ & $0 \cdot 23$ & $2 \cdot 654$ & 1.099 & $0 \cdot 717$ \\
\hline
\end{tabular}

*\#No.- \#No. are the upper and the lower sieve numbers, respectively, for a uniform sand.

$\dagger$ The classification is according to ASTM D422-63 (ASTM, 2007).
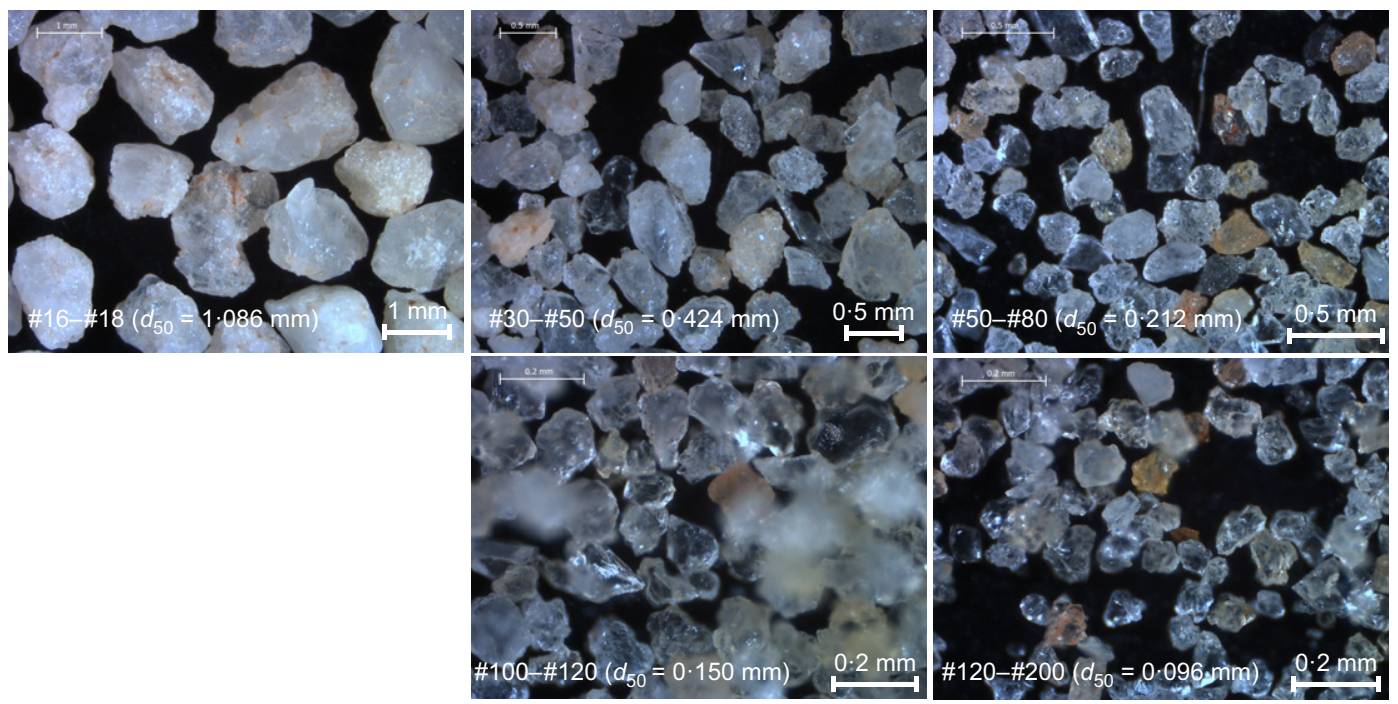

Fig. 1. Micrographs of uniform silica sands of five different particle sizes 
small particle size in a binary mixture. The particle size distributions of binary mixtures with four different particle size ratios are presented in Fig. 2. The minimum void ratio and the maximum void ratio of four series of binary mixtures were determined according to method 2A of ASTM (2006a) and method B of ASTM (2006b), respectively. The minimum and the maximum void ratios of these binary mixture samples are presented in Table 2.

\section{Drained triaxial compression testing}

A conventional triaxial device was used to study the drained shear behaviour of binary silica sand mixtures. All tests were performed on cylindrical specimens $(50 \mathrm{~mm}$ dia. and $100 \mathrm{~mm}$ high) under the confining stress of $200 \mathrm{kPa}$. In total, 25 triaxial tests were performed. All specimens were prepared by the moist tamping method with the undercompaction technique introduced by Ladd (1978). The moist soil with a moisture content of $5 \%$ was placed in the split mould and then compacted to a specified density in five layers. A 3\% under-compaction ratio, defined as the difference in density between successive layers, was used in the sample preparation to improve the uniformity within specimens. The moist tamping method is able to minimise particle segregation because of capillarity. Because of the advantage in creating uniform samples and avoiding particle



(a)

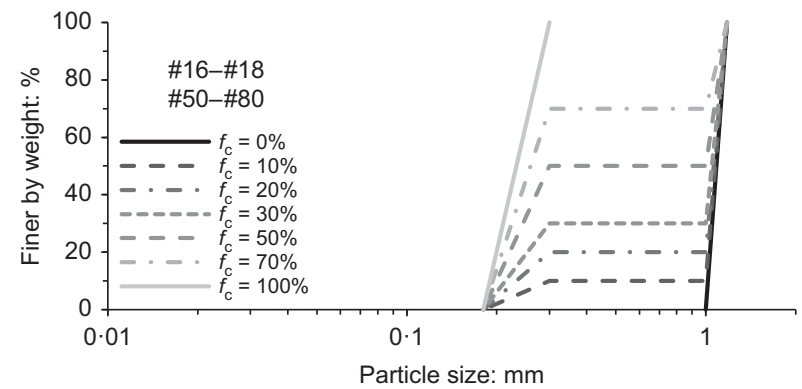

(b)



(c)

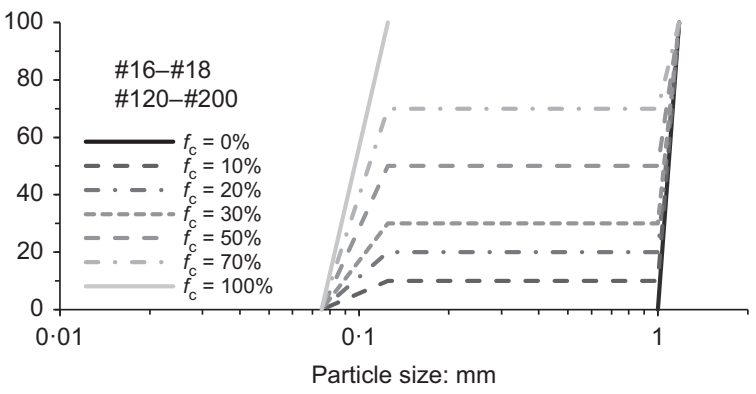

(d)

Fig. 2. The grain size distributions of binary mixtures with four different particle size ratios: (a) ratio-2.56; (b) ratio-4.67; (c) ratio-7.93; (d) ratio-11·31

Table 2. List of index properties of binary mixtures tested

\begin{tabular}{|c|c|c|c|c|c|}
\hline Symbol & Mixture series* & Size ratio ${ }^{\dagger} d_{50 \_c o a r s e} / d_{50 \_ \text {fine }}$ & $f_{\mathrm{c}}: \%$ & $e_{\max }$ & $e_{\min }$ \\
\hline \multirow[t]{5}{*}{ Ratio-2.56 } & \#16-\#18 & $2 \cdot 56$ & 10 & $0 \cdot 874$ & 0.603 \\
\hline & $\# 30-\# 50$ & & 20 & $0 \cdot 828$ & $0 \cdot 566$ \\
\hline & & & 30 & $0 \cdot 800$ & $0 \cdot 540$ \\
\hline & & & 50 & $0 \cdot 802$ & $0 \cdot 548$ \\
\hline & & & 70 & $0 \cdot 873$ & 0.620 \\
\hline \multirow[t]{5}{*}{ Ratio-4.67 } & \#16-\#18 & $4 \cdot 67$ & 10 & $0 \cdot 830$ & $0 \cdot 571$ \\
\hline & \#50-\#80 & & 20 & $0 \cdot 734$ & 0.508 \\
\hline & & & 30 & $0 \cdot 703$ & $0 \cdot 491$ \\
\hline & & & 50 & $0 \cdot 725$ & $0 \cdot 501$ \\
\hline & & & 70 & $0 \cdot 858$ & 0.592 \\
\hline \multirow[t]{5}{*}{ Ratio-7.93 } & $\# 16-\# 18$ & $7 \cdot 93$ & 10 & 0.795 & 0.547 \\
\hline & $\# 100-\# 120$ & & 20 & 0.679 & 0.452 \\
\hline & & & 30 & 0.635 & $0 \cdot 393$ \\
\hline & & & 50 & $0 \cdot 648$ & $0 \cdot 463$ \\
\hline & & & 70 & $0 \cdot 821$ & $0 \cdot 585$ \\
\hline \multirow{5}{*}{ Ratio-11·31 } & \#16-\#18 & $11 \cdot 31$ & 10 & $0 \cdot 797$ & 0.523 \\
\hline & $\# 120-\# 200$ & & 20 & 0.659 & $0 \cdot 408$ \\
\hline & & & 30 & 0.583 & 0.335 \\
\hline & & & 50 & $0 \cdot 600$ & 0.415 \\
\hline & & & 70 & $0 \cdot 776$ & 0.517 \\
\hline
\end{tabular}

*The \#16-\#18 sand is referred to as 'coarse' particles; \#30-\#50 sand, \#50-\#80 sand, \#100-\#120 sand and \#120-\#200 sand are referred to as 'fine' particles.

$\dagger d_{50}$ coarse is the mean size of large particles and $d_{50 \_ \text {fine }}$ is the mean size of small particles. 

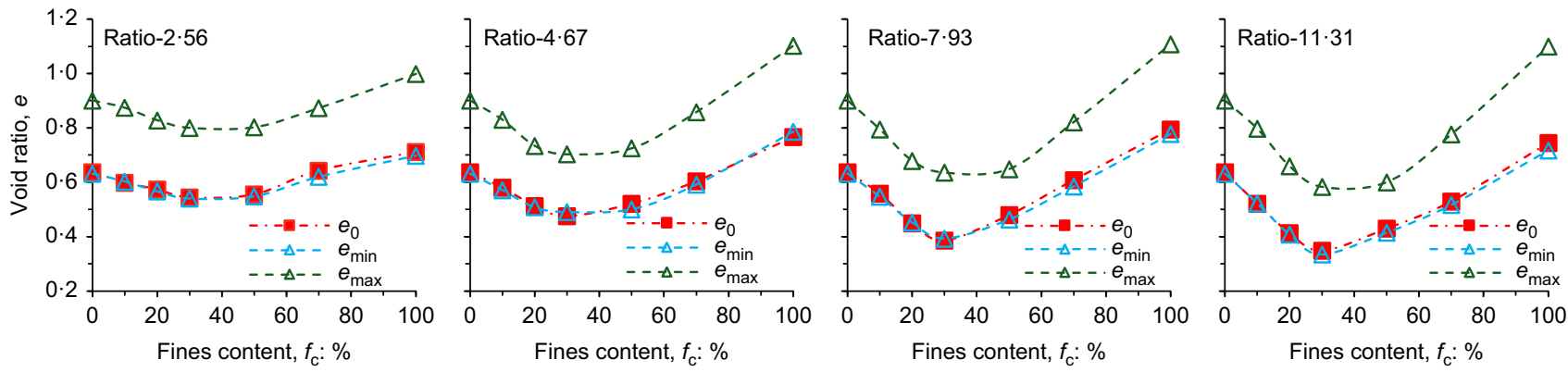

Fig. 3. The initial void ratios $e_{0}$ of all samples

segregation, the moist tamping method using undercompaction is preferred in the sample preparation for sand-silt mixtures (e.g. Huang et al., 2004; Yang et al., 2006; Wei \& Yang, 2019).

Note that the minimum and the maximum void ratios of the samples were obtained using dry sand (according to ASTM (2006a) and ASTM (2006b)). The initial void ratios $e_{0}$ of all samples after preparation using the moist tamping method are plotted in Fig. 3, compared with the measured values of $e_{\min }$ and $e_{\max }$. As shown in Fig. 3, the value of $e_{0}$ for all samples is nearly the same as that of $e_{\min }$, which indicates that all samples have the same initial relative density of around $97 \%$.

After the sample preparation and installation into the triaxial cell, the specimen was saturated by flushing with carbon dioxide gas and then flushing with deaired water, followed by back-pressure saturation to achieve a value of Skempton's $B$ parameter of greater than $0 \cdot 96$. Then the specimen was isotropically consolidated under the desired effective confining stress. After consolidation, the specimen was sheared until failure by compressing it at a constant vertical displacement rate of $0.2 \mathrm{~mm} / \mathrm{min}$ under the confining stress. All samples were under a drained condition during the course of shearing. Particle breakage was not observed in any test. The results of the triaxial tests are summarised in Table 3.

Major and minor principal effective stresses are denoted by $\sigma_{1}^{\prime}$ and $\sigma_{3}^{\prime}$. Axial and volumetric strains are denoted by $\varepsilon_{\mathrm{a}}$ and $\varepsilon_{\mathrm{v}}$. Contractive strains are considered to be positive and dilative strains are considered negative.

\section{TEST RESULTS}

Stress-strain and volumetric change responses

Figure 4 shows deviatoric stress $q\left(q=\sigma_{1}^{\prime}-\sigma_{3}^{\prime}\right)$ and volumetric strain $\left(\varepsilon_{\mathrm{v}}\right)$ plotted against axial strain $\left(\varepsilon_{\mathrm{a}}\right)$ relationships for these four series of binary mixtures. As shown in Fig. 4, all specimens exhibited a softening behaviour in the plot of stress against strain and a dilative behaviour in the plot of volumetric strain against axial strain. Following the initial slight contraction at a small axial strain, dilation then commences. After the onset of dilation, this continues during shearing until the deviatoric stress mobilises to the peak value. After the peak deviatoric stress, the stress decreases and appears to approach a stable value, indicating that a critical state will be reached at larger strains.

Figure 4 shows that fines content affects peak shear strength and volumetric response. There is a general trend of the effect of $f_{\mathrm{c}}$ on peak shear strength: at low $f_{\mathrm{c}}$, the peak strength is reduced with an increase of $f_{\mathrm{c}}$ until a particular $f_{\mathrm{c}}$ termed the transitional fines content, $f_{\text {th }}$, is reached. After that, a further increase in $f_{\mathrm{c}}$ results in an increase of the peak strength. Herein, the transitional fines content $f_{\text {th }}$ is defined as the point at which the trend reverses.
Considering volumetric response, it was observed that the curve of $\varepsilon_{\mathrm{v}}$ against $\varepsilon_{\mathrm{a}}$ moves upwards with increase of $f_{\mathrm{c}}$ until a transitional fine content $f_{\text {th }}$ is reached; after that the curve tends to move downwards with further increasing $f_{\mathrm{c}}$. For example, for ratio- 4.67 mixtures, the curve moves upwards from the curve of $f_{\mathrm{c}}=0$ to the top one $\left(f_{\mathrm{c}}=30 \%\right)$ with increase of $f_{\mathrm{c}}$. Then, with further increasing $f_{\mathrm{c}}$, the curve moves downwards from the top one to the lowest one $\left(f_{\mathrm{c}}=100 \%\right)$. This observation implies that increasing $f_{\mathrm{c}}$ could suppress dilation when $f_{\mathrm{c}}<f_{\mathrm{th}}$; on the other hand, increasing $f_{\mathrm{c}}$ could promote dilation when $f_{\mathrm{c}}>f_{\text {th }}$.

Figure 4 shows particle size ratio has a significant influence on the characteristics of the stress-strain curve for high $f_{\mathrm{c}}$ samples (i.e. $f_{\mathrm{c}} \geq 50 \%$ ). However, particle size ratio has little influence for low $f_{\mathrm{c}}$ samples $\left(f_{\mathrm{c}}<30 \%\right)$.

It was observed that for high $f_{\mathrm{c}}$ samples, increasing particle size ratio intensifies the post-peak softening of the stress-strain curves (i.e. brittle characteristic). It can be found that for the samples of ratio-11.31 at high $f_{\mathrm{c}}$, the strain softening is so intense that it exhibits a collapse behaviour of the stress-strain curves. Correspondingly, visible shear bands were observed in these tests. For low $f_{\mathrm{c}}$ samples, however, increasing particle size ratio has little influence on the degree of post-peak softening of the stressstrain curve.

The reason could be that, for low $f_{\mathrm{c}}$, the large particle network dominates the behaviour. The large particles are of the same size in the mixtures of four different particle size ratios. In contrast, for high $f_{\mathrm{c}}$, the small particle matrix dominates the behaviour. Also, the sizes of the small particles are dramatically different in the mixtures of the four size ratios.

\section{Stress-dilatancy plot}

The stress-dilatancy evolution of mixtures is presented in Fig. 5 for each particle size ratio. For clarity, the data for $f_{\mathrm{c}} \leq f_{\text {th }}$ and $f_{\mathrm{c}} \geq f_{\text {th }}$ are shown separately in Fig. 5 .

All stress-dilatancy plots show that there is an initial non-linear part of the curve before the stress ratio $\eta\left(\eta=q / p^{\prime}\right)$ has reached around $\eta=0 \cdot 8$. Then there is a consistent increase of dilatancy $D\left(D=-\mathrm{d} \varepsilon_{\mathrm{v}} / \mathrm{d} \varepsilon_{\mathrm{q}}\right)$ with an increase in the stress ratio $\eta=q / p^{\prime}$, prior to the maximum dilatancy. Here, $p^{\prime}$ is mean effective stress $\left(p^{\prime}=\left(\sigma_{1}^{\prime}+2 \sigma_{3}^{\prime}\right) / 3\right)$ and $\varepsilon_{\mathrm{q}}$ is deviator strain $\left(\varepsilon_{\mathrm{q}}=\varepsilon_{\mathrm{a}}-\varepsilon_{\mathrm{v}} / 3\right)$.

Once $D$ reaches a peak $\left(D_{\max }\right)$, the curves go backwards, yielding a 'hook' in the curve as it approaches the critical state. This behaviour is in agreement with that of Erksak sand (Been \& Jefferies, 2004). Li \& Dafalias (2000) proposed a model to capture this behaviour.

As shown in Fig. 5, $D_{\max }$ and the corresponding peak stress ratio $\eta_{\max }$ on the stress-dilatancy plot vary with different $f_{\mathrm{c}}$. For $f_{\mathrm{c}} \leq f_{\mathrm{th}}$, the addition of fine particles reduces the values of $D_{\max }$ and the corresponding $\eta_{\max }$. For $f_{\mathrm{c}} \geq f_{\text {th }}$, further increasing $f_{\mathrm{c}}$ raises the values of $D_{\max }$ and the 
Table 3. Summary results of drained triaxial compression tests on the specimens of binary silica sand mixtures of various fines contents for four different particle size ratios

\begin{tabular}{|c|c|c|c|c|c|c|c|c|c|c|c|}
\hline \multirow[t]{4}{*}{ Samples } & \multirow{3}{*}{$\begin{array}{l}\text { Fines } \\
\text { content }\end{array}$} & \multicolumn{5}{|c|}{ Void ratio } & \multicolumn{5}{|c|}{ Shearing } \\
\hline & & \multirow[t]{2}{*}{ Initial } & \multirow[t]{2}{*}{ Consolidation } & \multirow{2}{*}{$\begin{array}{l}\text { Onset of } \\
\text { dilatancy }\end{array}$} & \multirow{2}{*}{$\begin{array}{l}\text { Peak } \\
\text { stress }\end{array}$} & \multirow{2}{*}{$\begin{array}{l}\text { Critical } \\
\text { state }\end{array}$} & \multicolumn{2}{|c|}{ Strain at peak stress } & \multirow{2}{*}{$\begin{array}{c}\text { Peak } \\
\text { friction angle }\end{array}$} & \multirow{2}{*}{$\begin{array}{l}\text { Max. } \\
\text { dilation angle }\end{array}$} & \multirow{2}{*}{$\begin{array}{l}\text { Critical state } \\
\text { friction angle }\end{array}$} \\
\hline & & & & & & & Axial & Volumetric & & & \\
\hline & $f_{\mathrm{c}}: \%$ & $e_{0}$ & $e_{\mathrm{c}}$ & $e_{\mathrm{f}}$ & $e_{\mathrm{p}}$ & $e_{\mathrm{cs}}$ & $\varepsilon_{\mathrm{a}}: \%$ & $\varepsilon_{\mathrm{v}}: \%$ & $\phi_{\mathrm{p}}:$ degrees & $\psi_{\mathrm{p}}:$ degrees & $\phi_{\mathrm{cv}}:$ degrees \\
\hline \#16-\#18 & - & 0.637 & 0.621 & $0 \cdot 617$ & 0.663 & $0 \cdot 727$ & $9 \cdot 5$ & $-2 \cdot 6$ & $38 \cdot 0$ & $11 \cdot 0$ & $32 \cdot 8$ \\
\hline$\# 16-\# 18$ & 10 & 0.599 & $0 \cdot 583$ & 0.579 & $0 \cdot 619$ & $0 \cdot 692$ & $10 \cdot 9$ & $-2 \cdot 5$ & $36 \cdot 9$ & $9 \cdot 3$ & $31 \cdot 6$ \\
\hline \multirow{5}{*}{ \#30-\#50 (Ratio-2·56) } & 20 & 0.573 & 0.558 & 0.553 & 0.584 & 0.643 & $10 \cdot 3$ & $-1 \cdot 7$ & $36 \cdot 0$ & $7 \cdot 7$ & $31 \cdot 5$ \\
\hline & 30 & $0 \cdot 544$ & $0 \cdot 531$ & $0 \cdot 527$ & $0 \cdot 561$ & $0 \cdot 611$ & $8 \cdot 2$ & $-1 \cdot 5$ & $37 \cdot 6$ & $9 \cdot 0$ & $33 \cdot 6$ \\
\hline & 50 & $0 \cdot 555$ & $0 \cdot 544$ & $0 \cdot 541$ & $0 \cdot 575$ & $0 \cdot 631$ & $8 \cdot 3$ & $-2 \cdot 0$ & $38 \cdot 1$ & $9 \cdot 9$ & $33 \cdot 6$ \\
\hline & 70 & 0.643 & 0.631 & 0.626 & 0.655 & $0 \cdot 713$ & $9 \cdot 0$ & $-1 \cdot 6$ & $37 \cdot 0$ & $8 \cdot 3$ & $33 \cdot 1$ \\
\hline & 100 & $0 \cdot 711$ & $0 \cdot 700$ & 0.696 & $0 \cdot 746$ & $0 \cdot 805$ & $9 \cdot 4$ & $-2 \cdot 7$ & $39 \cdot 0$ & $11 \cdot 7$ & $33 \cdot 6$ \\
\hline \#16-\#18 & 10 & $0 \cdot 580$ & $0 \cdot 562$ & $0 \cdot 558$ & $0 \cdot 603$ & $0 \cdot 665$ & $12 \cdot 2$ & $-2 \cdot 5$ & $36 \cdot 2$ & $8 \cdot 5$ & $31 \cdot 7$ \\
\hline \multirow{5}{*}{ \#50-\#80 (Ratio-4.67) } & 20 & $0 \cdot 513$ & $0 \cdot 499$ & $0 \cdot 494$ & $0 \cdot 517$ & $0 \cdot 569$ & $9 \cdot 0$ & $-1 \cdot 3$ & $36 \cdot 4$ & $7 \cdot 1$ & $31 \cdot 9$ \\
\hline & 30 & $0 \cdot 475$ & $0 \cdot 461$ & $0 \cdot 456$ & $0 \cdot 471$ & $0 \cdot 503$ & $8 \cdot 95$ & $-0 \cdot 7$ & $36 \cdot 6$ & $5 \cdot 2$ & $32 \cdot 8$ \\
\hline & 50 & $0 \cdot 521$ & $0 \cdot 512$ & $0 \cdot 508$ & $0 \cdot 528$ & $0 \cdot 559$ & $8 \cdot 7$ & $-0 \cdot 9$ & $36 \cdot 8$ & $6 \cdot 6$ & $33 \cdot 7$ \\
\hline & 70 & $0 \cdot 604$ & $0 \cdot 595$ & 0.591 & $0 \cdot 625$ & $0 \cdot 690$ & $8 \cdot 9$ & $-2 \cdot 1$ & $39 \cdot 2$ & $9 \cdot 6$ & $34 \cdot 5$ \\
\hline & 100 & $0 \cdot 767$ & $0 \cdot 756$ & $0 \cdot 752$ & $0 \cdot 812$ & $0 \cdot 894$ & $9 \cdot 2$ & $-3 \cdot 2$ & $40 \cdot 0$ & $12 \cdot 3$ & $35 \cdot 0$ \\
\hline \#16-\#18 & 10 & $0 \cdot 558$ & $0 \cdot 542$ & $0 \cdot 535$ & $0 \cdot 561$ & $0 \cdot 601$ & $11 \cdot 8$ & $-1 \cdot 5$ & $35 \cdot 2$ & $8 \cdot 0$ & $31 \cdot 8$ \\
\hline \#100-\#120 (Ratio- & 20 & $0 \cdot 449$ & $0 \cdot 435$ & $0 \cdot 428$ & $0 \cdot 464$ & $0 \cdot 500$ & $14 \cdot 4$ & $-1 \cdot 8$ & $34 \cdot 9$ & $6 \cdot 7$ & $32 \cdot 1$ \\
\hline \multirow{4}{*}{$7 \cdot 93)$} & 30 & $0 \cdot 386$ & $0 \cdot 376$ & $0 \cdot 370$ & $0 \cdot 375$ & $0 \cdot 408$ & $6 \cdot 5$ & -0.03 & $35 \cdot 9$ & $4 \cdot 6$ & $31 \cdot 3$ \\
\hline & 50 & $0 \cdot 479$ & $0 \cdot 470$ & $0 \cdot 465$ & $0 \cdot 484$ & $0 \cdot 525$ & $7 \cdot 9$ & $-1 \cdot 2$ & $38 \cdot 4$ & $8 \cdot 2$ & $34 \cdot 8$ \\
\hline & 70 & $0 \cdot 608$ & $0 \cdot 598$ & 0.593 & $0 \cdot 617$ & $0 \cdot 677$ & $7 \cdot 3$ & $-1 \cdot 2$ & $38 \cdot 1$ & $10 \cdot 1$ & $33 \cdot 3$ \\
\hline & 100 & $0 \cdot 794$ & $0 \cdot 784$ & $0 \cdot 780$ & 0.829 & 0.903 & $7 \cdot 8$ & $-2 \cdot 0$ & $39 \cdot 9$ & $12 \cdot 6$ & $35 \cdot 2$ \\
\hline \multirow{6}{*}{$\begin{array}{l}\# 16-\# 18 \\
\# 120-\# 200 \text { (Ratio- } \\
11 \cdot 31 \text { ) }\end{array}$} & 10 & $0 \cdot 521$ & $0 \cdot 505$ & $0 \cdot 502$ & $0 \cdot 550$ & $0 \cdot 597$ & $11 \cdot 0$ & $-3 \cdot 0$ & $38 \cdot 1$ & $11 \cdot 0$ & $33 \cdot 0$ \\
\hline & 20 & $0 \cdot 414$ & $0 \cdot 404$ & $0 \cdot 402$ & $0 \cdot 433$ & $0 \cdot 484$ & $9 \cdot 5$ & $-1 \cdot 7$ & $36 \cdot 9$ & $7 \cdot 1$ & $31 \cdot 9$ \\
\hline & 30 & 0.349 & 0.339 & 0.333 & 0.339 & $0 \cdot 356$ & $7 \cdot 8$ & $-0 \cdot 03$ & $36 \cdot 8$ & $4 \cdot 0$ & $31 \cdot 7$ \\
\hline & 50 & $0 \cdot 430$ & $0 \cdot 422$ & $0 \cdot 420$ & $0 \cdot 435$ & $0 \cdot 459$ & $5 \cdot 65$ & $-0 \cdot 9$ & $38 \cdot 4$ & $9 \cdot 2$ & $33 \cdot 1$ \\
\hline & 70 & $0 \cdot 530$ & $0 \cdot 523$ & $0 \cdot 519$ & $0 \cdot 544$ & $0 \cdot 621$ & $5 \cdot 72$ & $-1 \cdot 32$ & $40 \cdot 1$ & $12 \cdot 0$ & $35 \cdot 2$ \\
\hline & 100 & 0.744 & $0 \cdot 734$ & $0 \cdot 730$ & $0 \cdot 770$ & 0.865 & $7 \cdot 0$ & $-2 \cdot 1$ & $41 \cdot 1$ & $13 \cdot 3$ & $35 \cdot 1$ \\
\hline
\end{tabular}



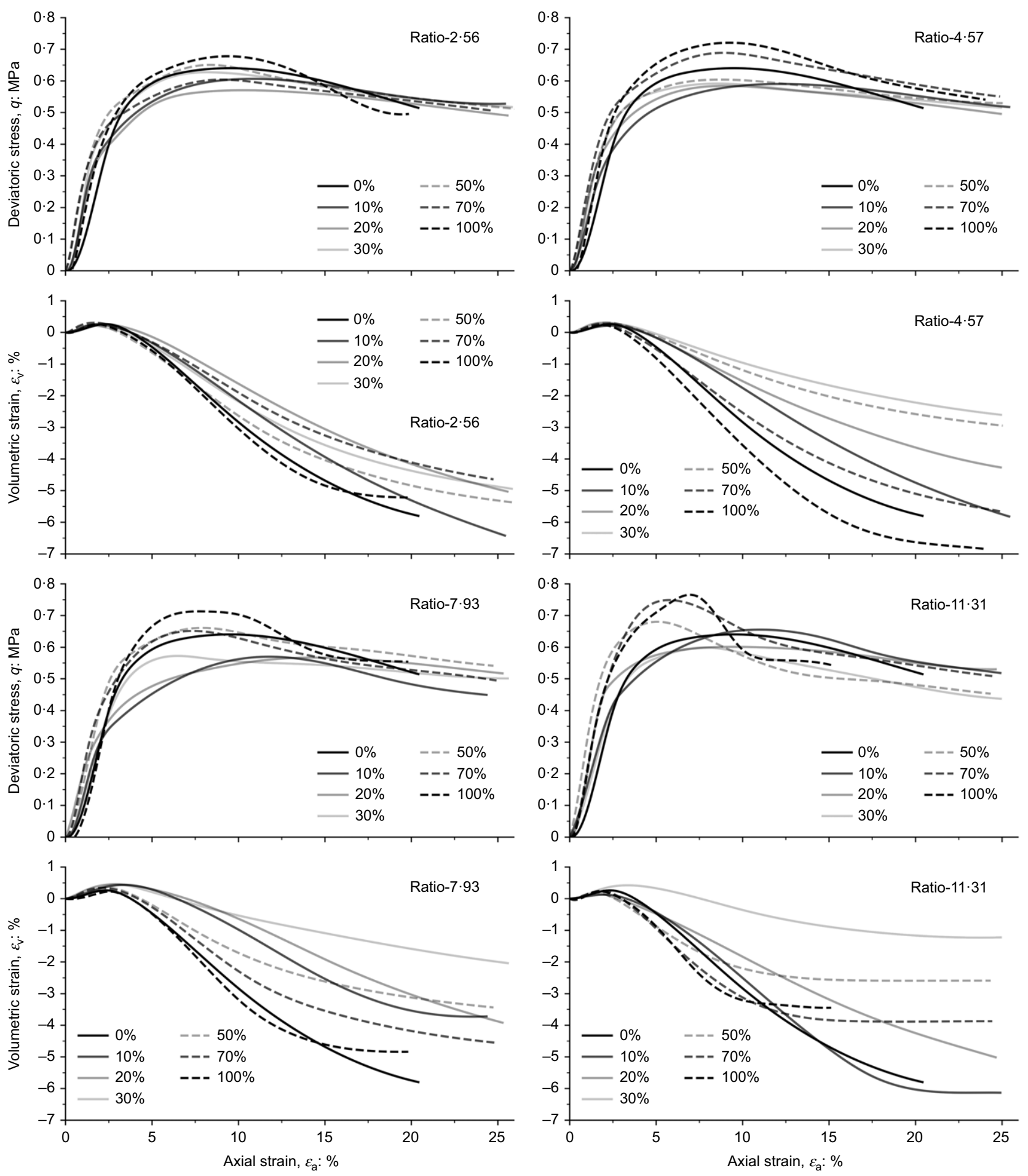

Fig. 4. Experimental results of the drained triaxial compression tests on binary mixtures of various fines contents and particle size ratios

corresponding $\eta_{\max }$. This behaviour agrees with the effect of fines content on peak shear strength and volumetric response mentioned previously. The measured values of $D_{\max }$ and the corresponding $\eta_{\max }$ will be used to calculate the maximum dilation angle $\psi_{\mathrm{p}}$ and the peak friction angle $\phi_{\mathrm{p}}$, respectively, which will be discussed in the section headed 'Maximum dilation angle and peak friction angle'.

\section{ANALYSES OF TEST RESULTS}

Based on the test results, the critical state void ratio, the critical state friction angle, the maximum dilation angle and the peak friction angle can be obtained. In this section, the effects of fines content and particle size ratio on the critical state void ratio, the critical state friction angle, the maximum dilation angle, the peak friction angle and the stressdilatancy relation will be discussed.

\section{Determination of critical state}

Critical state is defined as the state at which the soil continues to deform in shear at constant stress (effective mean stress and shear stress) and constant void ratio (Roscoe et al., 1958). In this study, the triaxial tests were performed up to the maximum axial strain in the apparatus $(25 \%)$. At this strain, however, the samples have not yet reached the critical 
state. As suggested by Murthy et al. (2007) and Carrera et al. (2011), it is necessary to extrapolate the stress-strain data to reach the critical state. An extrapolation method, as used by Indraratna et al. (2014) and Xiao et al. (2016), was applied to determine the critical state for the tests in the current study. Typical examples for extrapolating the data to critical state are given in the Appendix. The extrapolation is more reliable if localisation has not yet occurred at $25 \%$ strain. However, the extrapolation is not reliable if the occurrence of localisation is before $25 \%$ axial strain and accompanied by large non-homogeneous deformation. In the current tests, localisation was observed in some samples (nine out of 25), especially the samples with large particle size ratios at very high or very low fines contents. In the other 16 samples (mostly in the transitional region of fines content), localisation was not observed.

For these samples with localisation, the above-mentioned method is no longer applicable owing to the nonhomogeneous deformation. For these cases with localisation, another method, as suggested by investigators (Nova, 1982; Harehdasht et al., 2017), has been adopted. This method requires multiple test results from the same sample under different confining stresses, instead of a single test, to determine the critical state. Examples using the multiple tests method are given in the Appendix.

\section{Critical state void ratio}

Background. The effects of fines content and particle size ratio on random close packing density (corresponding to minimum void ratio) have been studied by McGeary (1961) for steel shots and by Kwan et al. (2013) for glass beads, as shown in Fig. 6, which shows that the minimum void ratio of a binary packing depends on fines content $f_{\mathrm{c}}$ and particle size ratio. It was found that the void ratio of binary mixtures decreases with increasing particle size ratio, for any given fines content. Similar results have been found in soil mixtures (Yilmaz, 2009). The relationship between void ratio and $f_{\mathrm{c}}$ has two features. (a) It is a V-shaped curve. The lowest void ratio corresponds to a transitional or threshold fines content. (b) The curve has two regions separated by the transitional fines content - a coarse-particle-dominant region for lower $f_{\mathrm{c}}$ and a fine-particle-dominant region for higher $f_{\mathrm{c}}$.

The question raised now is whether the special features for minimum void ratio plotted against $f_{\mathrm{c}}$ are also applicable to critical state void ratio. There have been a lot of experimental data showing that the relationship between $e_{\mathrm{cs}}$ and $f_{\mathrm{c}}$ has a V-shaped characteristic (e.g. Zlatović \& Ishihara, 1995; Thevanayagam et al., 2002; Naeini \& Baziar, 2004; Yang, 2004; Papadopoulou \& Tika, 2008; Carrera et al., 2011; Dash \& Sitharam, 2011; Kwa \& Airey, 2016). For example, Fig. 7 shows the critical void ratios for five different types of
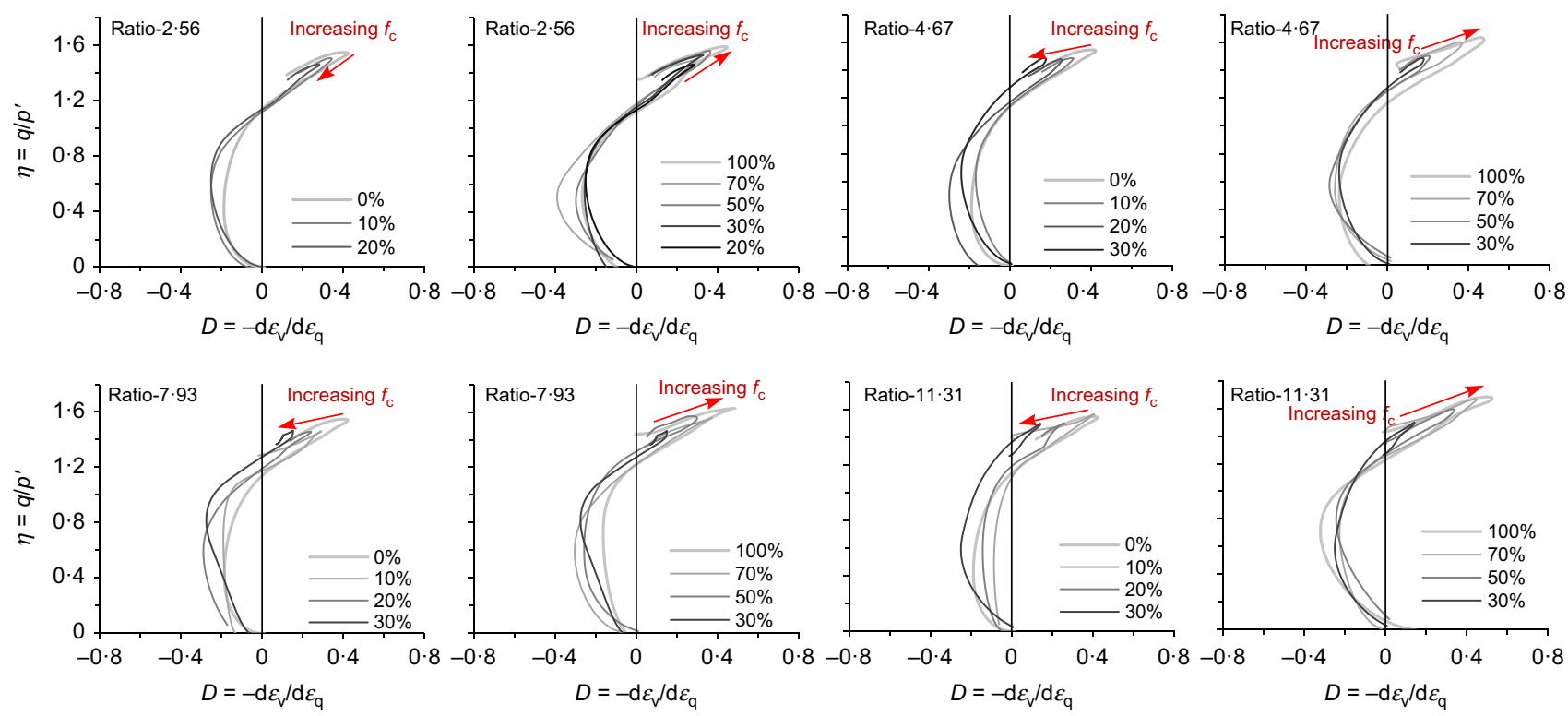

Fig. 5. The stress-dilatancy plots for binary mixtures of various fines contents and particle size ratios



(a)

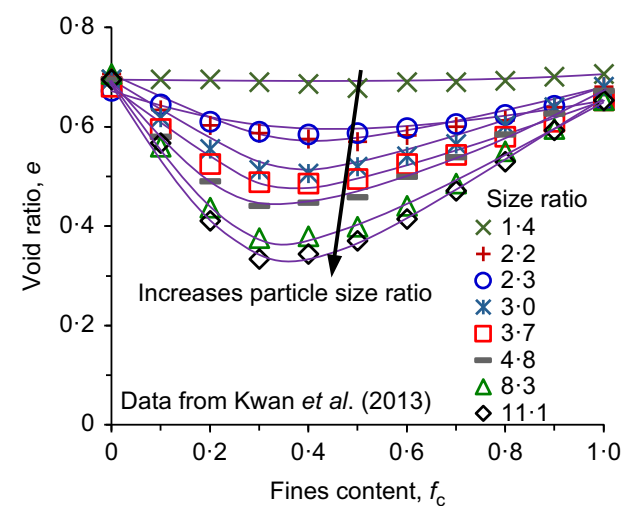

(b)

Fig. 6. The minimum void ratios of binary granular mixtures with various particle size ratios: (a) steel shots; (b) glass beads 
sand-silt mixtures. The V-shaped characteristics are exhibited in the relationship between critical void ratio and fines content.

The plots of critical void ratios under the mean effective stress $p_{\mathrm{cs}}^{\prime}$ of $40 \mathrm{kPa}$ in Fig. 7 were from five types of binary mixtures with different particle size ratios (ranges from $7 \cdot 6$ to 26) (Thevanayagam et al., 2002; Naeini \& Baziar, 2004; Yang, 2004; Papadopoulou \& Tika, 2008; Carrera et al., 2011). The particle size ratio is 26 for Stava tailings mixtures (Carrera et al., 2011), 25 for foundry sand-silt mixtures (Thevanayagam et al., 2002), 15 for Assyros sandsilt mixtures (Papadopoulou \& Tika, 2008), 14 for Hokksund sand-silt mixtures (Yang, 2004) and 7.6 for Ardebil sand-silt mixtures (Naeini \& Baziar, 2004). Fig. 7 shows that there is no trend of the particle size ratio effect on the critical state void ratios of these mixtures, because each mixture has a different material type.

Thus, in order to study the effect of particle size ratio, the binary mixtures are constructed using the components of the same material type so that the effect of particle size ratio can be studied with less influence of other unknown factors. For this purpose, a series of drained compression triaxial tests on binary silica sand mixture of the same material type are conducted.

Results of $\mathrm{e}_{c s}$. The results of critical state void ratios $e_{\mathrm{cs}}$ in this study are plotted in Fig. 8(a). The void ratios of samples at the end of testing $e_{\text {end }}$ are also plotted in this figure for comparison. The values of $e_{\mathrm{cs}}$ and $e_{\mathrm{end}}$ for each test are very

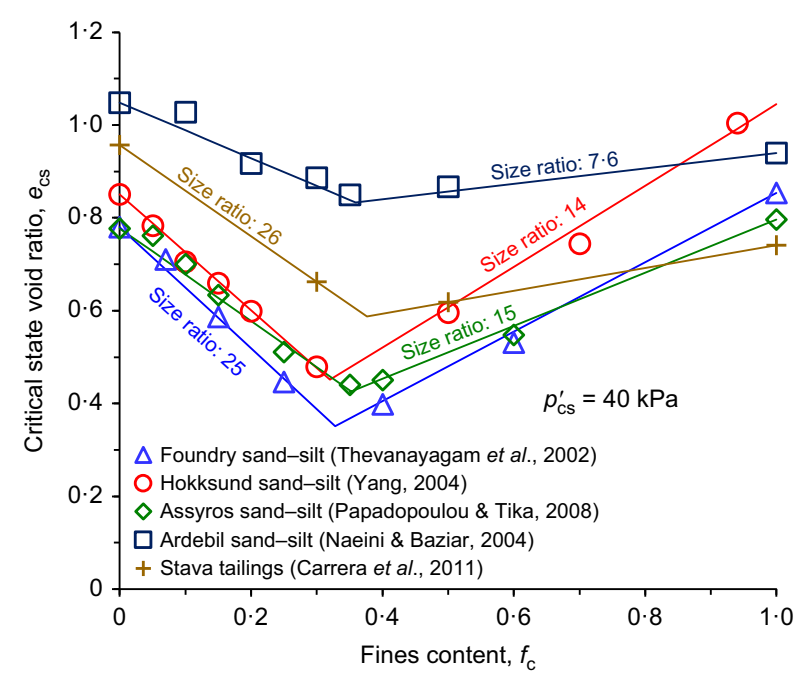

Fig. 7. The critical state void ratios of five different types of sand-silt mixtures with various fines contents close. It is observed that the critical state void ratio is dependent on fines content and particle size ratio.

Considering the effect of fines content, the relationship between $e_{\mathrm{cs}}$ and fines content has a $\mathrm{V}$-shaped character. On the left side, increasing $f_{\mathrm{c}}$ results in decreasing $e_{\mathrm{cs}}$ of the binary mixture. On the right side, increasing $f_{\mathrm{c}}$ results in increasing $e_{\mathrm{cs}}$ of the binary mixture. This V-shaped pattern of fines content influence has also been observed in many experimental investigations on silt-sand mixtures (e.g. Zlatović \& Ishihara, 1995; Thevanayagam et al., 2002; Naeini \& Baziar, 2004; Yang, 2004; Papadopoulou \& Tika, 2008; Carrera et al., 2011; Dash \& Sitharam, 2011; Kwa \& Airey, 2016).

Considering the effect of particle size ratio, as shown Fig. 8(a), the curve of $e_{\mathrm{cs}}$ against $f_{\mathrm{c}}$ moves downwards with increasing particle size ratio. The minimum and maximum void ratios of the mixtures used in this study (listed in Table 2) are plotted in Figs 8(b) and 8(c). Comparing the three void ratios in Figs 8(a)-8(c), it is observed that the influences of fines content and particle size ratio on $e_{\mathrm{cs}}$ are similar to these on $e_{\max }$ and $e_{\min }$, even though the three density states $e_{\mathrm{cs}}, e_{\max }$ and $e_{\min }$ are achieved by three different mechanical processes. The similarity between the changes of $e_{\mathrm{cs}}$ and $e_{\min }$ due to fines content has also been found by other investigators (Chang \& Yin, 2011; Chang \& Meidani, 2013; Yin et al., 2014).

The packing potential indices of the three density states are further investigated. For a system of mixtures (i.e. mixtures with the same two components of various combinations), the upper and the lower bounds can be defined by particle packing theory (Westman \& Hugill, 1930; Furnas, 1931; De Larrard, 1999; Chang \& Deng, 2020). The void ratios of the binary mixtures with various $f_{\mathrm{c}}$ are between the upper and the lower bounds as the curve ADB shown in Fig. 9(a). The packing potential index $\Omega$ is defined as the ratio of area ADB to area $\mathrm{ACB}$, which is a material descriptor for a system of mixtures (Chang \& Deng, 2020). This index is a measure of volume reduction potential due to the mixing of two components of a binary mixture system under a packing procedure, which is a simple scalar and can be directly obtained from experimental data. The value of packing potential index $\Omega$ is between 0 and 1 . The higher value of $\Omega$ indicates a higher potential of volume reduction of the mixtures.

The packing potential indices of the three density states $\left(e_{\mathrm{cs}}, e_{\max }\right.$ and $\left.e_{\min }\right)$ for the four particle size ratios are plotted in Fig. 9(b). It is interesting to observe that, for each size ratio, the values of these packing potential indices $\left(\Omega_{\mathrm{cs}}, \Omega_{\max }\right.$ and $\left.\Omega_{\mathrm{min}}\right)$ are nearly identical for the three density states $\left(e_{\mathrm{cs}}\right.$, $e_{\max }$ and $\left.e_{\min }\right)$. The value of $\Omega$ seems to be affected mainly by the composition of a mixture, but affected marginally by the mechanical procedures that lead to the three density states. This implies that fines content plays the same role in the reduction of void ratio of a binary mixture for these three



(a)

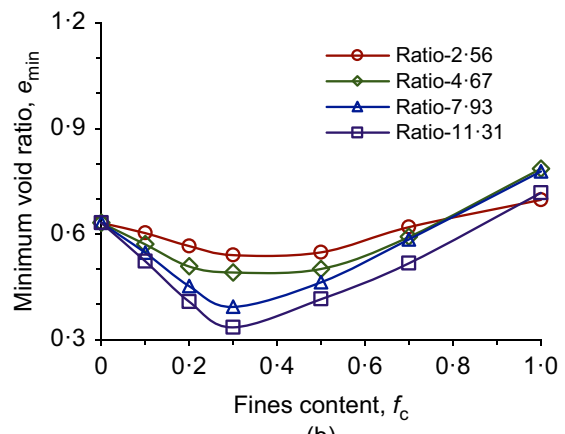

(b)

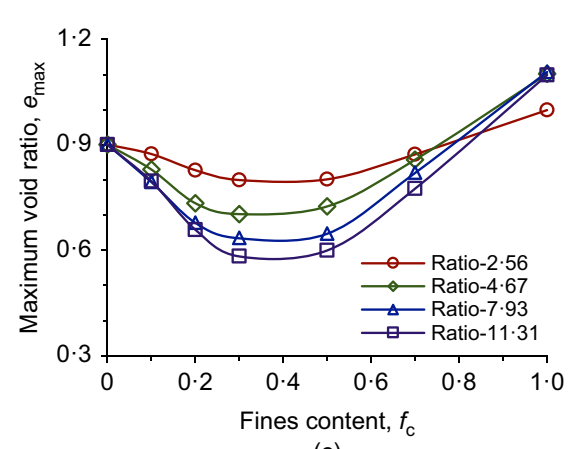

(c)

Fig. 8. The effects of fines content and particle size ratio on: (a) critical state void ratio; (b) minimum void ratio; (c) maximum void ratio 


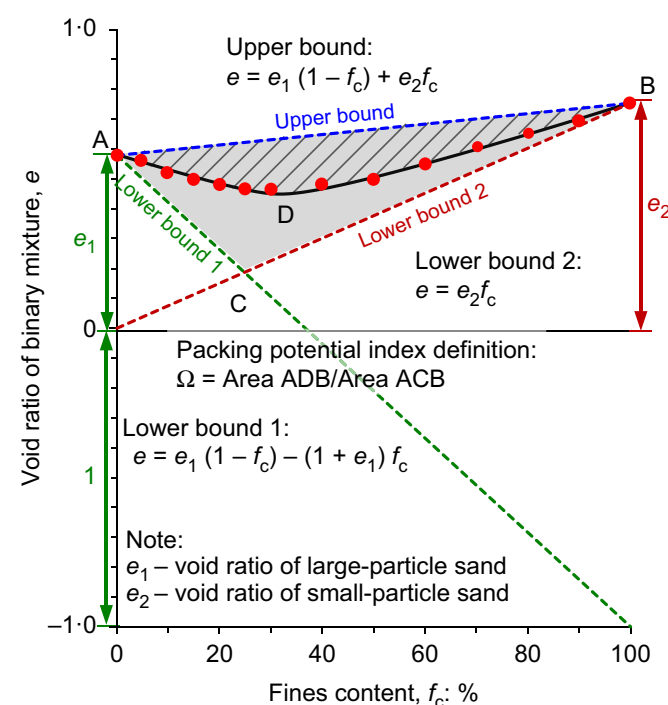

(a)

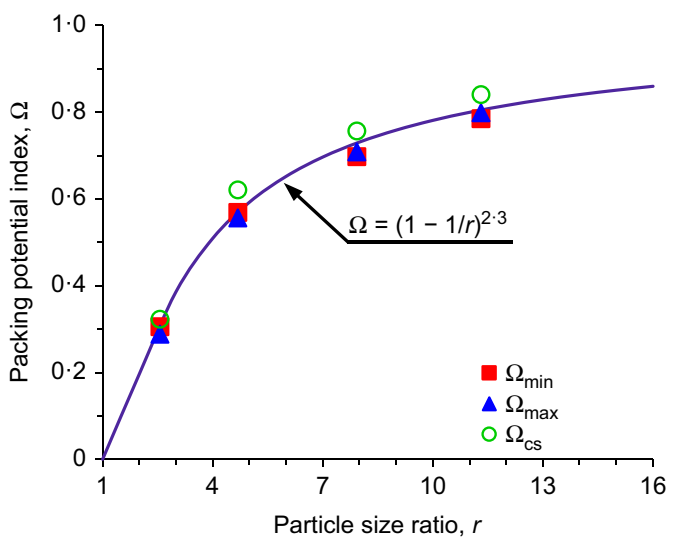

(b)

Fig. 9. (a) The definition of packing potential index and (b) packing potential indices for the void ratios of a system of mixtures at three density states

density states. This particular feature is useful for predicting the critical void ratios as a function of particle size ratio and fines content.

\section{Critical state friction angle}

The influence of fines content on critical state friction angle $\phi_{\mathrm{cv}}$ are presented in Fig. 10. There are three regions, as described below.

(a) For low fines content, $\phi_{\mathrm{cv}}$ values of binary mixtures remain close to that of the large-particle sand and are almost independent of fines content. This could be because the resistance at critical state for these fines contents is dominated by the contacts between large particles, while small particles located in the voids are inactive.

(b) For high fines content, $\phi_{\mathrm{cv}}$ values of binary mixtures remain close to that of the fine sand and are also almost independent of fines content. This could be because the resistance at critical state for these fines contents is dominated by the contacts between small particles, while large particles embed in the matrix formed by small particles.

(c) The third region is a transition region. The $\phi_{\mathrm{cv}}$ of binary mixtures is a transition value from the $\phi_{\mathrm{cv}}$ of large-particle sand to the $\phi_{\mathrm{cv}}$ of the fine sand. In the transition region, with increasing fines content, the resistance of a binary mixture at critical state is initially dominated by large particle-to-large particle contacts, transitioning to large particle-to-small particle contacts, and finally to small particle-to-small particle contacts.

It is noted that in Fig. 8, the transitional fines content is defined as a point (reverse of behaviour). Now, in Fig. 10, there is no abrupt change of behaviour for critical state friction angle; instead, the behaviour change is gradual. Thus, a transition region is defined between the lower transitional fines content and the upper transitional fines content.

As shown in Fig. 10, the lower and upper transitional fines contents and the width of transition region vary with different particle size ratio. Particle size ratio might be a key factor controlling the transition region, as suggested by Ueda et al. (2011).



Fig. 10. The influence of fines content on critical state friction angles of binary mixtures with four different particle size ratios

As shown in Fig. 10, the transition occurs at lower fines contents with smaller particle size ratios. The reason might be that at smaller particle size ratios the fine particles are too large to fit in the voids between large particles, and consequently the network of large particles is altered by the filled fine particles. Thus, the resistance of the binary mixture begins to be dominated by the contacts between large particle-to-small particle at lower fines contents, as suggested by Shire et al. (2014). Therefore, the transition occurs at lower fines contents. At larger particle size ratios, on the contrary, the fines fit well in the voids between large particles, 
and consequently the network of large particles is not altered until the voids are entirely filled up. Therefore, the transition occurs at higher fines content for the large particle size ratios compared to that for the small particle size ratios.

This transitional behaviour of critical state friction angle varying with fines content is consistent with the influence of fines content on residual friction angle in experimental investigations (Vallejo, 2001; Polito \& Sibley, 2020) and in the discrete-element method (DEM) simulation by Ueda et al. (2011) for simple and direct shear tests.

However, it was observed from other DEM simulations that the critical state friction angle is roughly independent of fines content and particle size ratio (Zhu et al., 2020) and independent of the particle size distribution (Yan \& Dong, 2011; Azéma et al., 2017). An experimental investigation on glass beads by Harehdasht et al. (2017) also showed the grading independence.

The independence of fine content on $\phi_{\mathrm{cv}}$ could be caused by the fact that the two particle components in a system of mixtures have the same critical state friction angle. In DEM simulation, the particles normally have identical shape, stiffness and inter-particle coefficient of friction. These identical properties for the two components cause the $\phi_{\mathrm{cv}}$ to be independent of fines content. In the DEM simulation by Ueda et al. (2011), however, the inter-particle coefficients of friction are assigned to be different for the two components, which causes the friction angle to be dependent on fines content. In the current tests, the two particle components in a system of mixtures have different critical state friction angles due to the difference in particle angularity. The finer component is a bit more angular than the coarser component and therefore the $\phi_{\mathrm{cv}}$ is higher for pure fines than for pure coarse particles. Hence, the value of $\phi_{\mathrm{cv}}$ is dependent on fines content in the current test results.

\section{Maximum dilation angle and peak friction angle}

The dilation angle $(\psi)$ was calculated using the following relationship proposed by Vermeer \& de Borst (1984)

$$
\sin \psi=\frac{-\left(\mathrm{d} \varepsilon_{\mathrm{v}} / \mathrm{d} \varepsilon_{\mathrm{a}}\right)}{2-\left(\mathrm{d} \varepsilon_{\mathrm{v}} / \mathrm{d} \varepsilon_{\mathrm{a}}\right)}
$$

The results of maximum dilation angle $\psi_{\mathrm{p}}$ are presented in Fig. 11(a). It was observed that fines content has significant influence on $\psi_{\mathrm{p}}$, especially for the larger particle size ratios namely, ratio- $4 \cdot 67$, ratio-7.93 and ratio- $11 \cdot 31$. For these three particle size ratios, the relationship between $\psi_{\mathrm{p}}$ and fines content has an obvious change around $f_{\mathrm{c}}=30 \%: \psi_{\mathrm{p}}$ decreases with an increase in fines content for $f_{\mathrm{c}}<30 \%$, while $\psi_{\mathrm{p}}$ increases with an increase in fines content for $f_{\mathrm{c}}>30 \%$. The smallest $\psi_{\mathrm{p}}$ occurred at the fines content of $30 \%$. For the ratio-2.56 results, the relationship between $\psi_{\mathrm{p}}$ and fines content is different from those of the other three ratios. $\psi_{\mathrm{p}}$ decreases with an increase in fines content for $f_{\mathrm{c}}<20 \%$. The smallest $\psi_{\mathrm{p}}$ occurred at the fines content of $20 \%$. For $f_{\mathrm{c}}>20 \%, \psi_{\mathrm{p}}$ increases with an increase in fines content in general, except for $f_{\mathrm{c}}=70 \%$.

No obvious trend was observed for the particle size ratio effect on $\psi_{\mathrm{p}}$ for $f_{\mathrm{c}}<30 \%$. However, some trends were observed for $f_{\mathrm{c}} \geq 30 \%$. At $f_{\mathrm{c}}=30 \%, \psi_{\mathrm{p}}$ decreases with an increase in particle size ratio. The trend evolves and becomes opposite when $f_{\mathrm{c}}$ is above $50 \%$, when $\psi_{\mathrm{p}}$ increases with an increase in particle size ratio.

The mechanism of the above-mentioned behaviour will be discussed in the section headed 'Discussion on the mechanism for the influences of fines content and particle size ratio on drained shear behaviour'.

The results of peak friction angle $\phi_{\mathrm{p}}$ were presented in Fig. 11(b). For all particle size ratios, at low fines content, $\phi_{\mathrm{p}}$ decreases slightly with increasing fines content. With further increasing fines content, $\phi_{\mathrm{p}}$ is in transition to approach the $\phi_{\mathrm{p}}$ of the small particle size sand. But the trend for the effect of particle size ratio on the value of $\phi_{\mathrm{p}}$ was not found.

Bolton (1986) proposed an empirical formulation to describe the stress-dilatancy relation given by

$$
\phi_{\mathrm{p}}=\phi_{\mathrm{cv}}+b \psi_{\mathrm{p}}
$$

where parameter $b$ is a dilatancy parameter which implies the contribution of dilatancy to the peak strength. The values of $b$ were calculated using the above equation and are presented in Fig. 11(c). There is little variation in the values of $b$ at low or high fines content, which is consistent with the statement made by Xiao et al. (2017) that the effect of $f_{\mathrm{c}}$ on the value of $b$ is negligible. However, Xiao et al. (2017) made this observation only in relation to their data for Fujian sand mixtures, for $f_{\mathrm{c}} \leq 20 \%$. Fig. 11(c) clearly shows that in the transitional fines content region (around 30\%), values of $b$ are much greater than those in low and high fines content regions, and increase with increasing particle size ratio. The large values of $b$ show that the contribution of dilatancy to the peak strength is different between the transitional $f_{\mathrm{c}}$ region and the other two $f_{\mathrm{c}}$ regions. The different contribution of dilatancy to the peak strength indicated that the mechanisms of dilatancy must be different between the transitional $f_{\mathrm{c}}$ region and the other two $f_{\mathrm{c}}$ regions, which will be discussed in the following section.

\section{Transitional fines content}

The transitional fine content is different for different soil behaviours. The transitional fines contents of silica sand are listed in Table 4 for $e_{\min }, e_{\max }, e_{\mathrm{cs}}, \phi_{\mathrm{cv}}, \psi_{\mathrm{p}}$ and parameter $b$.

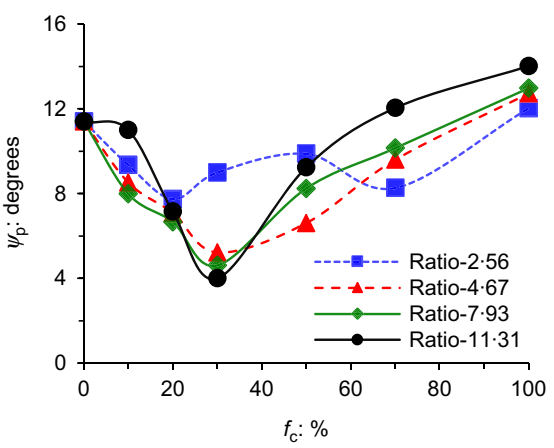

(a)

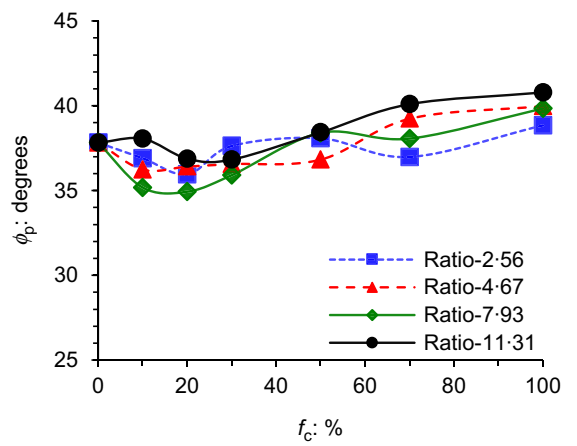

(b)



(c)

Fig. 11. The influence of fines content on: (a) the maximum dilation angle, $\psi_{\mathrm{p}}$ : (b) the peak friction angle, $\phi_{\mathrm{p}}$; (c) the dilatancy parameter $b$ in Bolton's stress-dilatancy relation, for binary mixtures with four different particle size ratios 
Table 4. The transitional fines contents $f_{\text {th }}$ for different soil behaviours with different particle size ratios

\begin{tabular}{|c|c|c|c|c|}
\hline Soil behaviour & $\begin{array}{c}f_{\text {th }}: \% \\
\text { Ratio- } 2 \cdot 56\end{array}$ & $\begin{array}{c}f_{\text {th }}: \% \\
\text { Ratio-4.67 }\end{array}$ & $\begin{array}{c}f_{\mathrm{th}}: \% \\
\text { Ratio- } 7 \cdot 93\end{array}$ & $\begin{array}{c}f_{\text {th }}: \% \\
\text { Ratio- } 11 \cdot 31\end{array}$ \\
\hline $\begin{array}{l}e_{\min } \\
e_{\max } \\
e_{\mathrm{cs}} \\
\phi_{\mathrm{cv}} \\
\psi_{\mathrm{p}} \\
b\end{array}$ & $\begin{array}{c}30-50 \\
30-50 \\
20-50 \\
20-30 \\
20 \\
10-30\end{array}$ & $\begin{array}{c}20-50 \\
30-50 \\
30 \\
20-50 \\
30 \\
20-50\end{array}$ & $\begin{array}{c}30 \\
30 \\
30 \\
30-50 \\
30 \\
20-50\end{array}$ & $\begin{array}{c}30 \\
30 \\
30 \\
30-70 \\
30 \\
20-50\end{array}$ \\
\hline
\end{tabular}

For $e_{\min }, e_{\max }, e_{\mathrm{cs}}$ and $\psi_{\mathrm{p}}$, the curves of the evolutions with fines content are generally $\mathrm{V}$-shaped, and the lowest points were selected as transitional fines contents. However, for some curves, the V-shape characteristic is blunt. In this case, a transitional fines content region is estimated, in which the lowest point is located.

For $\phi_{\mathrm{cv}}$, the curves do not have the V-shape characteristic (see Fig. 10). The shape of curves is two steps connected by a ramp. The curve changes gradually from a coarse-particledominant behaviour to a fine-particle-dominant behaviour. Thus, a transition region is defined between the lower transitional fines content and the upper transitional fines content, as listed in Table 4.

For parameter $b$, Fig. 11(c) clearly shows that in the transitional fines content region (around 30\%), values of $b$ are much greater than those in low- and high-fines-content regions, and increase with increasing particle size ratio. In this transitional region, the behaviour is very different from those in other regions. The transitional regions were estimated and are listed in Table 4.

Table 4 shows that the transitional fines content is dependent on the type of soil behaviour. There is no unique transitional fines content that can be defined for a binary mixture.

\section{DISCUSSION ON THE MECHANISM FOR THE INFLUENCES OF FINES CONTENT AND PARTICLE SIZE RATIO ON DRAINED SHEAR BEHAVIOUR}

A dense, uniform sand sample shearing to critical state successively experiences a hardening process and a softening process, in which a shear band usually occurs. The mechanism that ends up with the formation of shear bands is the result of the build-up of particle columns during the hardening process and their collapse during the softening process (Iwashita \& Oda, 2000).

According to Iwashita \& Oda (2000), in the hardening process up to failure, particles are rearranged in chains to form particle columns aligned in the direction of the major principal stress axis, and the applied load is mainly transmitted through them in the form of force chains. As shown in Fig. 12(a), during the loading process, the pre-existing contacts are lost in the minor principal stress direction, but new contacts are formed in the major principal stress direction. Consequently, an elongated void is generated between two neighbouring columns. This is the mechanism that causes dilatancy before failure. Owing to the formation of particle columns and the elongated void parallel to the major principal stress direction, the packing structure becomes highly anisotropic. Such an anisotropic structure becomes gradually unstable because of the loss of surrounding contact points. Finally, the particle columns collapse by way of buckling, as shown in Fig. 12(b). The number of buckled columns increases during the loading process, which eventually leads to a peak stress failure. After peak stress, a

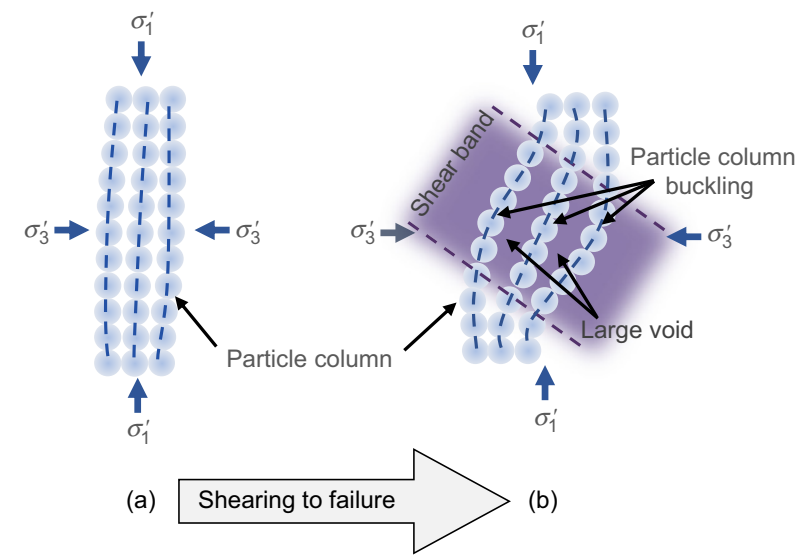

Fig. 12. A schematic diagram illustrating the mechanism for dilatancy: (a) build-up of particle columns; (b) buckling particle columns

new packing structure is re-constructed during the softening process. The main process then is the continued buckling of particle columns gradually concentrated in a narrow shear band, which causes the growth of large voids between the buckling columns and particle rotation. Finally, the structure reaches a dynamically stable condition at the critical state. During the critical state, the build-up and collapse of particle columns maintains equilibrium within persistent shear bands. The dilatancy is balanced with the contraction so that the overall volumetric strain remains unchanged, resulting in a constant void ratio.

The mechanism for the influences of fines content and particle size ratio could be explained from the perspective of particle column buckling, as illustrated in Fig. 13.

For large-particle-dominant binary mixtures (i.e. at low $f_{\mathrm{c}}$ ), as illustrated in Fig. 13(a), the particle columns are mainly formed by large particles during the hardening process. Small particles fill between the two neighbouring columns. Small particles laterally support the particle column to suppress buckling. Consequently, the generation of the elongated void between two neighbouring columns is limited. As the elongated void leads to dilatancy before failure, therefore, the dilatancy in the binary mixture is smaller than that in the uniform large-particle sand. Increasing fines content further suppresses dilatancy, and consequently results in a decrease of the maximum dilation angle, as shown in Fig. 11(a). Although the lateral support provided by the small particles makes the columns more difficult to buckle, at large strain, the columns still buckle and concentrate within a shear band, which exhibits a localised failure.

For the binary mixtures with a transitional fines content (i.e. $f_{\mathrm{c}}$ is around $30 \%$ ), as illustrated in Fig. 13(b), there could be fewer contacts between large particles owing to their being surrounded by small particles. However, the small particles are not yet sufficient to form a matrix. As a result, neither 




Fig. 13. The mechanisms for dilatancy and failure of binary sand mixtures in: (a) region of low fines content; (b) region of transitional fines content; (c) region of high fines content

large-particle nor small-particle columns can be built up during the hardening process. At this $f_{\mathrm{c}}$, the dilatancy may be caused mainly by particle rearrangement and their overriding each other during the shearing process. Hence, a smaller level of dilatancy is expected compared to that induced by column buckling. Since the dilatancy is caused by particles being overridden, the level of dilatancy is proportional to the size of particles. Therefore, the smallest dilatancy was observed in ratio- 11.31 test with $f_{\mathrm{c}}=30 \%$, compared with the other three ratios with this $f_{\mathrm{c}}$ (see Fig. 11(a)). Because there are no buckling particle columns, shear band formation is not as visible during the softening process. As a result, the authors observed that a diffuse-type failure was exhibited instead of a localised failure, as shown in Fig. 13(b).

For small-particle-dominant binary mixtures (i.e. at high $f_{\mathrm{c}}$ ), a matrix is formed by small particles, and large particles are floated into it, as illustrated in Fig. 13(c). During the hardening process, the particle columns are formed by small particles. Large elongated voids causing dilatancy gradually grow between two buckling small-particle columns. The number of small-particle columns increases with increasing $f_{\mathrm{c}}$. Therefore, the dilatancy also increases with increasing $f_{\mathrm{c}}$. Similarly to large-particle-dominant binary mixtures, small-particle-dominant binary mixtures exhibit a localised failure because buckling particle columns are eventually concentrated within a shear band.

As shown in Fig. 11(a), the uniform sand with smaller particle size has a higher maximum dilation angle, which was consistent with the observations on glass beads and Peribonka sand reported by Harehdasht et al. (2017). Harehdasht et al. (2017) attributed the increase of dilation angle to the particle size effect. In the silica sand used in this study, the particle roundness generally increases with particle size; thus the effect is caused by both factors of particle size and particle roundness.

At very high $f_{\mathrm{c}}$, the packing structure for the binary sand mixture is nearly the same as that of uniform fine sand. Therefore, in this case, a higher maximum dilation angle was observed for a mixture with larger particle size ratio (i.e. the smaller sized particle is more angular in shape) (see Fig. 11(a)).

As discussed above, the mechanism for dilatancy in the transitional fines content region is different from that in the regions of low and high fines content. Dilatancy in the transitional fines content region is governed by particle rearrangement and particles overriding each other, while dilatancy in the regions of low and high fines content is governed by the buckling columns. Therefore, as shown in Fig. 11(c), the values of $b$, implying the contribution of dilatancy to the peak strength, are clearly different between the transitional $f_{\mathrm{c}}$ region and the other $f_{\mathrm{c}}$ regions.

\section{CONCLUSIONS}

In this paper, the effects of fines content and particle size ratio on the drained shear behaviours were studied through a series of drained triaxial compression tests on dense binary silica sand mixtures with four different particle size ratios. The critical state and the strength-dilatancy behaviour were analysed. The mechanism for the effects of fines content and particle size ratio on drained shear behaviour was illustrated. Based on this study the major conclusions can be drawn as follows.

(a) It was observed that when $f_{\mathrm{c}}<f_{\text {th }}$, increasing $f_{\mathrm{c}}$ suppresses dilation; in contrast, when $f_{\mathrm{c}}>f_{\text {th }}$, increasing $f_{\mathrm{c}}$ promotes dilation. 
(b) It was observed that, for samples with high $f_{\mathrm{c}}$, increasing particle size ratio intensifies the post-peak softening of the stress-strain curves (i.e. brittle characteristic). For samples with low $f_{\mathrm{c}}$, however, increasing particle size ratio has little influence on the degree of post-peak softening of the stress-strain curve.

(c) Both fines content and particle size ratio have significant influence on critical state void ratio. It is interesting to note that the pattern of critical state void ratio is similar to that of minimum and maximum void ratios influenced by particle size ratio. The similar pattern might imply that fines content plays the same role in the reduction of void ratio of a binary mixture for these three density states.

(d) The value of $\phi_{\mathrm{cv}}$ of a mixture is influenced by its fines content, which can be divided into three regions: (a) in the region with low fines content, the $\phi_{\mathrm{cv}}$ values of binary mixtures are close to the $\phi_{\mathrm{cv}}$ of large particles; (b) in the region with high fines content, the $\phi_{\mathrm{cv}}$ values of binary mixtures are close to the $\phi_{\mathrm{cv}}$ of fine particles; (c) in the transition region, the $\phi_{\mathrm{cv}}$ values of binary mixtures represent a transition from the $\phi_{\mathrm{cv}}$ of the large particle sand to the $\phi_{\mathrm{cv}}$ of the fine sand.

(e) A general trend for the effect of fines content on $\psi_{\mathrm{p}}$ was observed. $\psi_{\mathrm{p}}$ decreases with an increase in fines content for $f_{\mathrm{c}}<30 \%$; however, $\psi_{\mathrm{p}}$ increases with an increase in fines content for $f_{\mathrm{c}}>30 \%$. The smallest $\psi_{\mathrm{p}}$ occurred at the fines content of $30 \%$. No obvious trend was observed for the particle size ratio effect on $\psi_{\mathrm{p}}$ for $f_{\mathrm{c}}<30 \%$. However, at $f_{\mathrm{c}}=30 \%$, there is a clear trend that $\psi_{\mathrm{p}}$ decreases with an increase in particle size ratio. The trend evolves and becomes opposite when $f_{\mathrm{c}}$ is above $50 \%$, when $\psi_{\mathrm{p}}$ increases with an increase in particle size ratio.

( $f$ ) It was found that the parameter $b$ in Bolton's stressdilatancy relation has a little variation in regions with low and high fines content. In the transitional fines content region, however, the parameter $b$ is much greater than that in the other two regions and increases with increasing particle size ratio.

(g) A mechanism was proposed to illustrate the influences of fines content and particle size ratio on the drained shear behaviour from the perspective of particle column

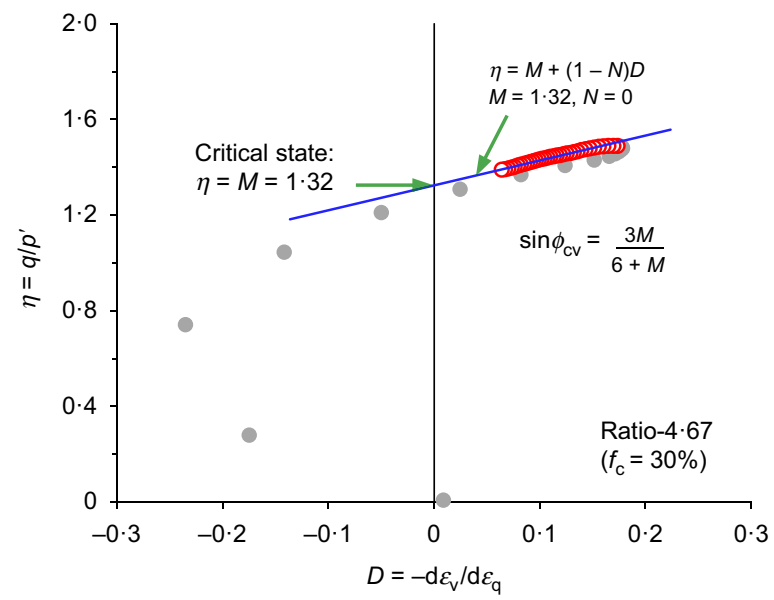

(a) buckling. Dilatancy in the transitional region of fines content is governed by the rearrangement of particles, which override each other. Dilatancy in the regions of low or high fines content, however, is governed by the buckling of particle columns. The influences of fines content and particle size ratio on dilatancy and value of $b$ in the Bolton's stress-dilatancy equation were explained by the proposed mechanism. The mechanism explained in this paper is only conjecture, and cannot be verified by triaxial tests alone. It needs to be further verified by other analyses, such as DEM simulation.

\section{ACKNOWLEDGEMENT}

This work was supported by the National Science Foundation of the USA under a research grant (CMMI-1917238). This support is gratefully acknowledged.

\section{APPENDIX. EXAMPLES TO DETERMINE THE CRITICAL STATE}

For samples without visualised localisation at large strain

For a sample without visualised deformation localisation, it is assumed that localisation is minute and the deformation is relatively uniform for the range of stress-strain curve between the peak stress and the end of test, which can be used to assess the critical state.

The critical state was determined by an extrapolating method described herein. The sample with ratio- 4.67 at $30 \% f_{\mathrm{c}}$ was taken as an example, as shown in Fig. 14. The critical state friction angle was first estimated with a stress-dilatancy analysis as shown in Fig. 14(a). In this analysis, Nova's stress-dilatancy relationship (Nova, 1982) was used to fit the stress-dilatancy data of post-peak stress

$$
\eta=M+(1-N) D
$$

where $M$ is the stress ratio at critical state and $N$ is a volumetric coupling coefficient. After the values of $M$ and $N$ had been obtained from fitting the data, the critical state friction angle $\phi_{\mathrm{cv}}$ was then obtained using the relationship $\sin \phi_{\mathrm{cv}}=3 M /(6+M)$ and listed in Table 3.

For convenience, a cosine function was used to extrapolate the post-peak stress-strain curve.

$$
\eta=\frac{\eta^{\text {peak }}+M}{2}+\frac{\eta^{\text {peak }}-M}{2} \cos \left(\frac{\varepsilon_{\mathrm{q}}-\varepsilon_{\mathrm{q}}^{\text {peak }}}{\varepsilon_{\mathrm{q}}^{c s}-\varepsilon_{\mathrm{q}}^{\text {peak }}} \times \pi\right) ; \varepsilon_{\mathrm{q}} \in\left[\varepsilon_{\mathrm{q}}^{\text {peak }}, \varepsilon_{\mathrm{q}}^{\text {cs }}\right]
$$



(c)

Fig. 14. An example of extrapolating the data to determine the critical state for a sample without visualised localisation: (a) stress-dilatancy analysis; (b) extrapolated stress-strain curve; (c) extrapolated volumetric strain curve 
where the superscripts 'peak' and 'cs' denote peak state and critical state, respectively. Figs 14(b) and 15(a) show that this cosine function is satisfactory to express the post-peak stress-strain curves. The deviator strain $\varepsilon_{\mathrm{q}}^{\mathrm{cs}}$, where the critical state occurs, was estimated by a regression analysis performed on the stress-strain data from the peak stress to the end of the test. The regression analysis minimises the sum of squared errors (SS)

$$
\mathrm{SS}\left(\varepsilon_{\mathrm{q}}^{\mathrm{cs}}\right)=\sum_{i}\left[\eta^{i}-\eta\left(\varepsilon_{\mathrm{q}}^{i}, \varepsilon_{\mathrm{q}}^{\mathrm{cs}}\right)\right]^{2}
$$

where $\eta^{i}$ and $\varepsilon_{\mathrm{q}}^{i}$ are the measured $i$ th point on the stress-strain curve. Substituting equation (4) into equation (3) and then integrating with respect to $\varepsilon_{\mathrm{q}}$, the expression of volumetric strain $\varepsilon_{\mathrm{v}}$ as a function of $\varepsilon_{\mathrm{q}}$ between peak state and critical state was obtained as follows

$$
\begin{aligned}
\varepsilon_{\mathrm{v}}= & \frac{M-\eta^{\text {peak }}}{2(1-N)}\left[\left(\varepsilon_{\mathrm{q}}-\varepsilon_{\mathrm{q}}^{\text {peak }}\right)+\frac{\varepsilon_{\mathrm{q}}^{\mathrm{cs}}-\varepsilon_{\mathrm{q}}^{\text {peak }}}{\pi} \sin \left(\frac{\varepsilon_{\mathrm{q}}-\varepsilon_{\mathrm{q}}^{\text {peak }}}{\varepsilon_{\mathrm{q}}^{\text {cs }}-\varepsilon_{\mathrm{q}}^{\text {peak }}} \times \pi\right)\right] \\
& +\varepsilon_{\mathrm{v}}^{\text {peak }}
\end{aligned}
$$

As shown in Figs 14(c) and 15(b), equation (6) matches the measured results well and can be used to extrapolate the curve
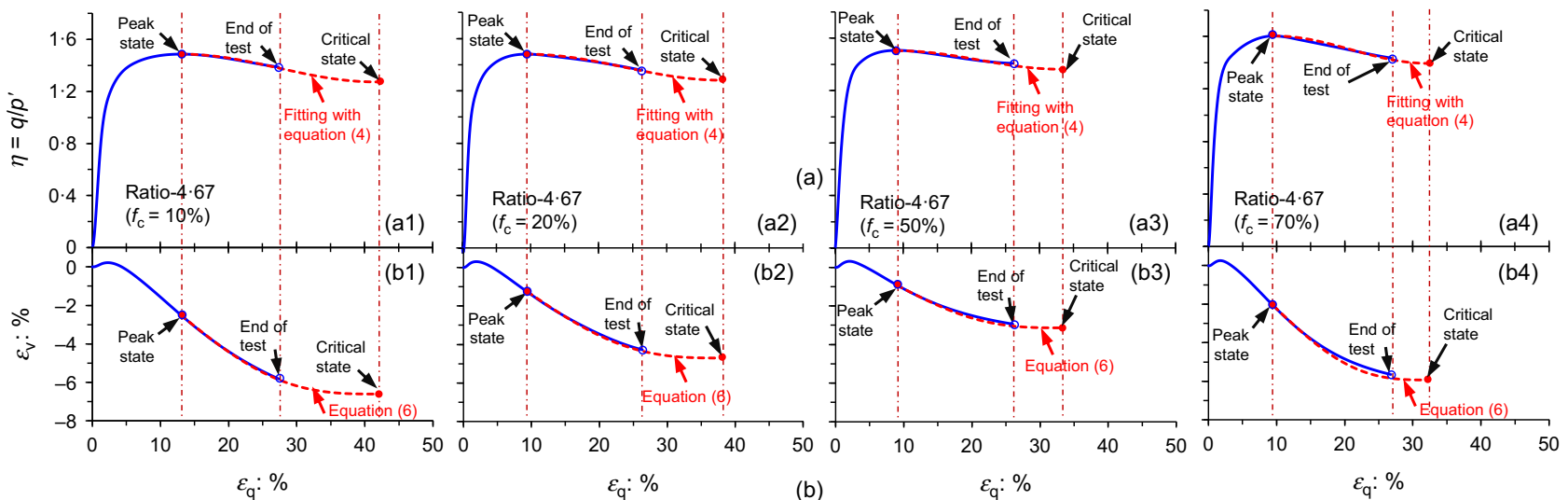

Fig. 15. Examples of extrapolating the data to determine the critical state for four samples of binary mixtures without visualised localisation: (a) extrapolated stress-strain curve; (b) extrapolated volumetric strain curve
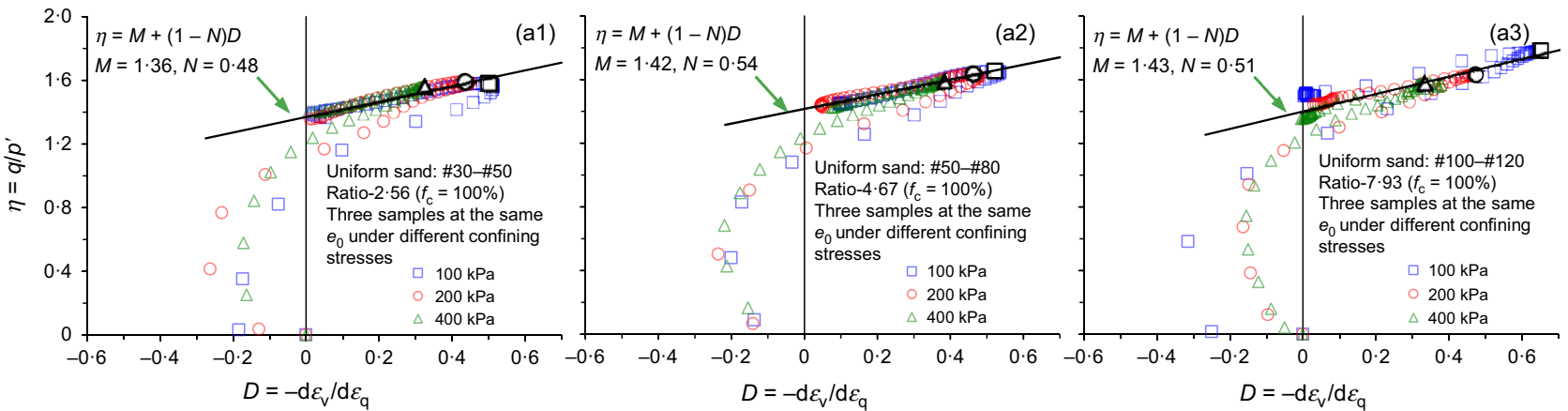

(a)
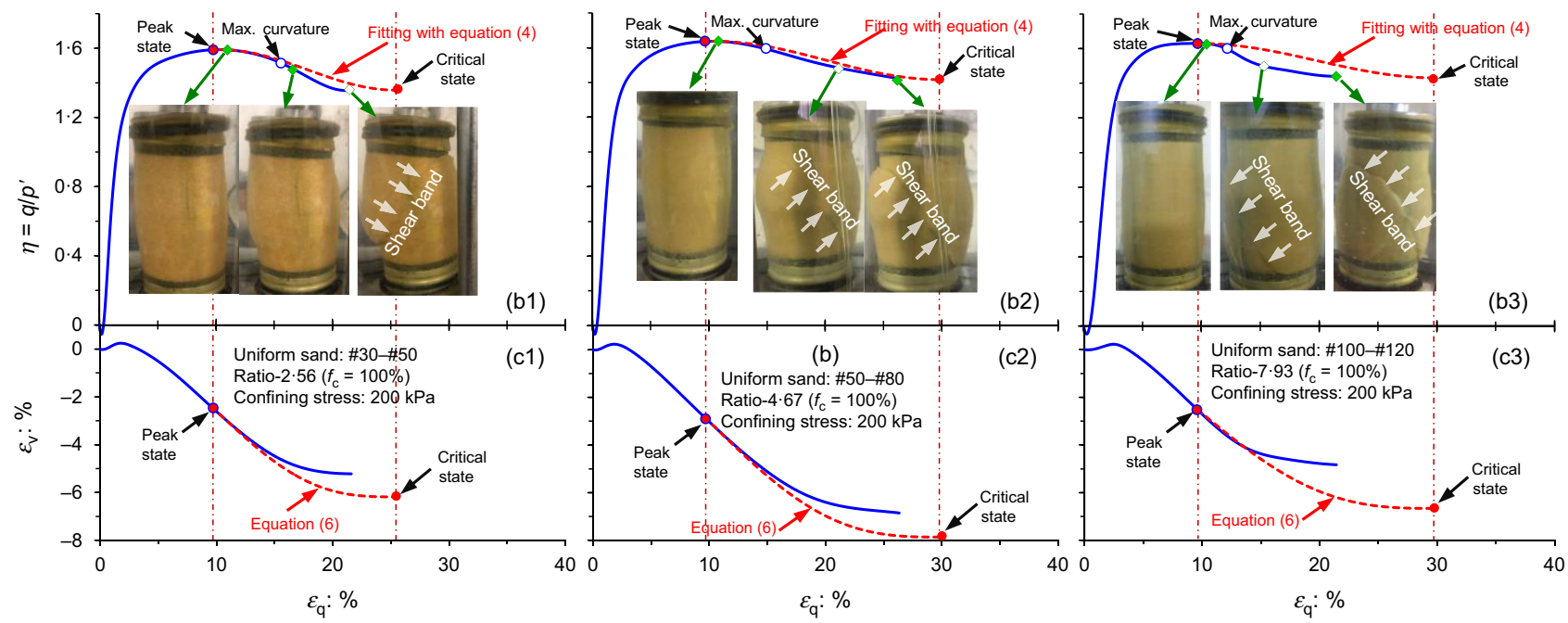

(c)

Fig. 16. Examples of extrapolating the data to critical state for the samples with deformation localisation: (a) stress-dilatancy analysis; (b) extrapolated stress-strain curve; (c) extrapolated volumetric strain curve 
of volumetric change response. Using this extrapolation method, the critical state void ratios for the samples without visualised deformation localisation were determined and are listed in Table 3.

\section{For samples with visualised localisation at large strain}

The sample deformation after the occurrence of localisation is not representative of a uniformly deformed material and thus cannot be used for extrapolation. Therefore, for a sample with visualised localisation, the critical state needs to be determined by using multiple test results (Nova, 1982; Harehdasht et al., 2017). In this study, test results were used from three different confining stresses (i.e. 100, 200 and $400 \mathrm{kPa}$ ). Assuming that the localisation that occurred is minute at peak stress state, the critical state stress ratio $M$ was obtained by fitting the peak points of three stress-dilatancy curves using equation (3), as shown in Fig. 16(a). After the stress-dilatancy relationship for each sample had been obtained, the critical state friction angle $\phi_{\mathrm{cv}}$ was then obtained using the relationship $\sin \phi_{\mathrm{cv}}=3 M /(6+M)$ and the values are listed in Table 3.

The initiation of localisation begins at peak stress state. The localisation becomes prominent after a point of maximum curvature, at which the stress-strain curve deviates from the smooth curve. After this point, a greater softening commences. The minute localisation propagates into a visualised shear band with abrupt stress reduction (see Fig. 16(b)). It is assumed that localisation is ineffective and the deformation is relatively uniform for the range of stress-strain curve between the peak stress and the point of maximum curvature. This portion of the measured curve can be used to assess the critical state.

As discussed previously, the post-peak stress-strain curve without visualised localisation can be expressed by a cosine function (equation (4)). Hence, this cosine function was also used to extrapolate the stress-strain curve between the peak stress and the point of maximum curvature for the samples with visualised deformation localisation. Using equation (4) with the determined $M$ from three test results, the critical state deviator strain $\varepsilon_{\mathrm{q}}^{\mathrm{cs}}$ was estimated by a regression analysis performed on the stress-strain data from the peak stress to the point of maximum curvature. The examples of the extrapolating stress-strain curves are shown in Fig. 16(b). The expression of volumetric strain $\varepsilon_{\mathrm{v}}$ as a function of $\varepsilon_{\mathrm{q}}$ between peak state and critical state was obtained based on the established stress-dilatancy relationship and the estimated $\varepsilon_{\mathrm{q}}^{\mathrm{cs}}$. The examples of the extrapolating volumetric strain curves are shown in Fig. 16(c). Using this extrapolation method, the critical state void ratios for the samples with visualised localisation were determined and are listed in Table 3.

\section{NOTATION}

$b$ dilatancy parameter

$D$ dilatancy or ratio of volumetric strain rate to deviator strain rate

$e_{0}, e_{\mathrm{cs}}$ initial void ratio, critical state void ratio, void ratio at end of test

$e_{\mathrm{c}}, e_{\mathrm{f}}, e_{\mathrm{p}}, e_{\mathrm{end}}$ void ratios after consolidation, at onset of dilatancy, at peak stress, at end of test

$e_{\min }, e_{\max }$ minimum and maximum void ratios

$f_{\mathrm{c}}$ fines content

$f_{\text {th }}$ transitional fines content

$M$ stress ratio at critical state

$N$ volumetric coupling coefficient

$p^{\prime}, p_{\mathrm{cs}}^{\prime} \quad$ mean effective stress, mean effective stress at critical state

$q$ deviatoric stress

$R_{\mathrm{W}}$ particle roundness

$\varepsilon_{\mathrm{a}}, \varepsilon_{\mathrm{v}}, \varepsilon_{\mathrm{q}}$ axial, volumetric and deviator strains

$\varepsilon_{\mathrm{q}}^{\text {peak }}, \varepsilon_{\mathrm{q}}^{\mathrm{se}}$ deviator strain at peak state and critical state

$\varepsilon_{\mathrm{v}}^{\text {peak }}$ volumetric at peak state

$\eta, \eta^{\text {peak }}$ stress ratio, stress ratio at peak state

$\sigma_{1}^{\prime}, \sigma_{3}^{\prime}$ major and minor principal effective stresses

$\phi_{\mathrm{p}}, \phi_{\mathrm{cv}}$ peak and critical state friction angles

$\psi_{\mathrm{p}}$ maximum dilation angle

$\Omega$ packing potential index

\section{REFERENCES}

ASTM (2006a). D4253-00: Standard test methods for maximum index density and unit weight of soils using a vibratory table. West Conshohocken, PA, USA: ASTM International.

ASTM (2006b). D4254-00: Standard test methods for minimum index density and unit weight of soils and calculation of relative density. West Conshohocken, PA, USA: ASTM International.

ASTM (2007). D422-63: Standard test method for particle-size analysis of soils. West Conshohocken, PA, USA: ASTM International.

ASTM (2014). D854-14: Standard test methods for specific gravity of soil solids by water pycnometer. West Conshohocken, PA, USA: ASTM International.

Azéma, E., Linero, S., Estrada, N. \& Lizcano, A. (2017). Shear strength and microstructure of polydisperse packings: the effect of size span and shape of particle size distribution. Phys. Rev. E 96, No. 2, 022902, https://doi.org/10.1103/ PhysRevE.96.022902.

Been, K. \& Jefferies, M. (2004). Stress-dilatancy in very loose sand. Can. Geotech. J. 41, No. 5, 972-989, https://doi.org/10. 1139/t04-038.

Bolton, M. D. (1986). The strength and dilatancy of sands. Géotechnique 36, No. 1, 65-78, https://doi.org/10.1680/geot. 1986.36.1.65.

Bouckovalas, G. D., Andrianopoulos, K. I. \& Papadimitriou, A. G. (2003). A critical state interpretation for the cyclic liquefaction resistance of silty sands. Soil Dyn. Earthq. Engng 23, No. 2, 115-125, https://doi.org/10.1016/S0267-7261(02)00156-2.

Carraro, J. A. H., Prezzi, M. \& Salgado, R. (2009). Shear strength and stiffness of sands containing plastic or nonplastic fines. J. Geotech. Geoenviron. Engng 135, No. 9, 1167-1178, https://doi.org/10.1061/(ASCE)1090-0241(2009)135.

Carrera, A., Coop, M. \& Lancellotta, R. (2011). Influence of grading on the mechanical behaviour of Stava tailings. Géotechnique 61, No. 11, 935-946, https://doi.org/10.1680/ geot.9.P.009.

Chang, C. S. \& Deng, Y. (2020). Packing potential index for binary mixtures of granular soil. Powder Technol. 372, 148-160, https://doi.org/10.1016/j.powtec.2020.06.005.

Chang, C. S. \& Meidani, M. (2013). Dominant grains network and behavior of sand-silt mixtures: stress-strain modeling. Int. J. Numer. Analyt. Methods Geomech. 37, No. 15, 2563-2589, https://doi.org/10.1002/nag.2152.

Chang, W. \& Phantachang, T. (2016). Effects of gravel content on shear resistance of gravelly soils. Engng Geol. 207, 78-90, https://doi.org/10.1016/j.enggeo.2016.04.015.

Chang, C. S. \& Yin, Z. Y. (2011). Micromechanical modeling for behavior of silty sand with influence of fine content. Int. J. Solids Structs 48, No. 19, 2655-2667, https://doi.org/10.1016/j.ijsolstr. 2011.05.014.

Dash, H. K. \& Sitharam, T. G. (2011). Undrained monotonic response of sand-silt mixtures: effect of nonplastic fines. Geomech. Geoengng 6, No. 1, 47-58, https://doi.org/10. 1080/17486021003706796.

De Larrard, F. (1999). Concrete mixture proportioning: a scientific approach. London, UK: E \& FN SPON.

Derkaoui, M., Missoum, H., Bendani, K. \& Belhouari, F. (2016). Shear behavior of sand-silt mixtures: a laboratory investigation of coastal silty sand soils of Mostaganem. Mar. Georesour. Geotechnol. 34, No. 7, 668-680, https://doi.org/10.1080/ 1064119X.2015.1070388.

Furnas, C. C. (1931). Grading aggregates I: mathematical relations for beds of broken solids of maximum density. Ind. Engng Chem. 23, No. 9, 1052-1058, https://doi.org/10.1021/ie50261a017.

Harehdasht, S. A., Karray, M., Hussien, M. N. \& Chekired, M. (2017). Influence of particle size and gradation on the stressdilatancy behavior of granular materials during drained triaxial compression. Int. J. Geomech. 17, No. 9, 04017077 , https://doi.org/10.1061/(ASCE)GM.1943-5622.0000951.

Huang, Y. T., Huang, A. B., Kuo, Y. C. \& Tsai, M. D. (2004). A laboratory study on the undrained strength of a silty sand from central western Taiwan. Soil Dyn. Earthq. Engng 24, No. 9, 733-743, https://doi.org/10.1016/j.soildyn.2004.06.013.

Indraratna, B., Nimbalkar, S., Coop, M. \& Sloan, S. W. (2014). A constitutive model for coal-fouled ballast capturing the effects 
of particle degradation. Comput. Geotech. 61, 96-107, https://doi.org/10.1016/j.compgeo.2014.05.003.

Iwashita, K. \& Oda, M. (2000). Micro-deformation mechanism of shear banding process based on modified distinct element method. Powder Technol. 109, No. 1-3, 192-205, https://doi. org/10.1016/S0032-5910(99)00236-3.

Jehring, M. M. \& Bareither, C. A. (2016). Tailings composition effects on shear strength behavior of co-mixed mine waste rock and tailings. Acta Geotech. 11, No. 5, 1147-1166, https://doi. org/10.1007/s11440-015-0429-1.

Kwa, K. A. \& Airey, D. W. (2016). Critical state interpretation of effects of fines in silty sands. Géotechnique Lett. 6, No. 1, 100-105, https://doi.org/10.1680/jgele.15.00176.

Kwan, A. K. H., Chan, K. W. \& Wong, V. (2013). A 3-parameter particle packing model incorporating the wedging effect. Powder Technol. 237, 172-179, https://doi.org/10.1016/ j.powtec.2013.01.043.

Ladd, R. S. (1978). Preparing test specimens using undercompaction. Geotech. Test. J. 1, No. 1, 16-23.

Li, X. S. \& Dafalias, Y. F. (2000). Dilatancy for cohesionless soils. Géotechnique 50, No. 4, 449-460, https://doi.org/10.1680/geot. 2000.50.4.449.

McGeary, R. K. (1961). Mechanical packing of spherical particles. J. Am. Ceram. Soc. 44, No. 10, 513-522, https://doi.org/10.1111/ j.1151-2916.1961.tb13716.x.

Murthy, T. G., Loukidis, D., Carraro, J. A. H., Prezzi, M. \& Salgado, R. (2007). Undrained monotonic response of clean and silty sands. Géotechnique 57, No. 7, 273-288, https://doi.org/ 10.1680/geot.2007.57.3.273.

Naeini, S. A. \& Baziar, M. H. (2004). Effect of fines content on steady-state strength of mixed and layered samples of a sand. Soil Dyn. Earthq. Engng 24, No. 3, 181-187.

Ni, Q., Tan, T. S., Dasari, G. R. \& Hight, D. W. (2004). Contribution of fines to the compressive strength of mixed soils. Géotechnique 54, No. 9, 561-569.

Nova, R. (1982). A constitutive model under monotonic and cyclic loading. In Soil mechanics - transient and cyclic loads (eds G. Pande and O.C. Zienkiewicz), pp. 343-373. New York, NY, USA: John Wiley \& Sons Ltd.

Papadopoulou, A. \& Tika, T. (2008). The effect of fines on critical state and liquefaction resistance characteristics of non-plastic silty sands. Soils Found. 48, No. 5, 713-725, https://doi.org/ 10.3208/sandf.47.887.

Patil, U. D., Hoyos, L. R., Puppala, A. J. \& Bheemasetti, T. V. (2018). Modeling stress-dilatancy behavior of compacted silty sand under suction-controlled axisymmetric shearing. Geotech. Geol. Engng 36, No. 6, 3961-3977, https://doi.org/10.1007/ s10706-018-0647-z.

Polito, C. P. \& Sibley, E. L. D. (2020). Threshold fines content and behavior of sands with nonplastic silts. Can. Geotech. J. 57, No. 3, 462-465, https://doi.org/10.1139/cgj-2018-0698.

Rahman, M. M., Lo, S. C. R. \& Dafalias, Y. F. (2014). Modelling the static liquefaction of sand with low-plasticity fines. Géotechnique 64, No. 11, 881-894, https://doi.org/10.1680/ geot.14.P.079.

Roscoe, K. H., Schofield, A. N. \& Wroth, C. P. (1958). On the yielding of soils. Géotechnique 8, No. 1, 22-53, https://doi.org/ 10.1680/geot.1958.8.1.22.

Salgado, R., Bandini, P. \& Karim, A. (2000). Shear strength and stiffness of silty sand. J. Geotech. Geoenviron. Engng 126, No. 5, 451-462, https://doi.org/10.1061/(ASCE)1090-0241 (2000)126:5(451).

Shire, T., O'Sullivan, C., Hanley, K. J. \& Fannin, R. J. (2014). Fabric and effective stress distribution in internally unstable soils.
J. Geotech. Geoenviron. Engng 140, No. 2, 04014072 , https://doi.org/10.1061/(ASCE)GT.1943-5606.0001184.

Thevanayagam, S., Shenthan, T., Mohan, S. \& Liang, J. (2002). Undrained fragility of clean sands, silty sands, and sandy silts. J. Geotech. Geoenviron. Engng 128, No. 10, 849-859, https://doi.org/10.1061/(ASCE)1090-0241(2002)128:10(849).

Ueda, T., Matsushima, T. \& Yamada, Y. (2011). Effect of particle size ratio and volume fraction on shear strength of binary granular mixture. Granul. Matter 13, No. 3, 731-742, https://doi.org/10.1007/s10035-011-0292-1.

Vallejo, L. E. (2001). Interpretation of the limits in shear strength in binary granular mixtures. Can. Geotech. J. 38, No. 5, 1097-1104, https://doi.org/10.1139/t01-029.

Vermeer, P. A. \& de Borst, R. (1984). Non-associated plasticity for soils, concrete and rock. HERON 29, No. 3, 1-64.

Wadell, H. (1935). Volume, shape, and roundness of quartz particles. J. Geol. 43, No. 3, 250-280.

Wei, X. \& Yang, J. (2019). Characterizing the effects of fines on the liquefaction resistance of silty sands. Soils Found. 59, No. 6, 1800-1812, https://doi.org/10.1016/j.sandf.2019.08.010.

Westman, A. E. R. \& Hugill, H. R. (1930). The packing of particles. J. Am. Ceram. Soc. 13, No. 10, 767-779, https://doi.org/10.1111/ j.1151-2916.1930.tb16222.x.

Xiao, Y., Liu, H., Ding, X., Chen, Y., Jiang, J. \& Zhang, W. (2016). Influence of particle breakage on critical state line of rockfill material. Int. J. Geomech. 16, No. 1, 04015031, https://doi.org/10.1061/(ASCE)GM.1943-5622.0000538.

Xiao, Y., Xiang, J., Liu, H. \& Ma, Q. (2017). Strength-dilatancy relation of sand containing non-plastic fines. Géotechnique Lett. 7, No. 2, 204-210, https://doi.org/10.1680/jgele.16.00144.

Yan, W. \& Dong, J. (2011). Effect of particle grading on the response of an idealized granular assemblage. Int. J. Geomech. 11, No. 4, 276-285, https://doi.org/10.1061/(ASCE)GM. 1943-5622.0000085.

Yang, S. L. (2004). Characterization of the properties of sand-silt mixtures. Trondheim, Norway: Norwegian University of Science and Technology.

Yang, S., Lacasse, S. \& Sandven, R. (2006). Determination of the transitional fines content of mixtures of sand and non-plastic fines. Geotech. Test. J. 29, No. 2, 1-6, https://doi.org/10.1520/ GTJ14010.

Yilmaz, Y. (2009). A study on the limit void ratio characteristics of medium to fine mixed graded sands. Engng Geol. 104, No. 3-4, 290-294, https://doi.org/10.1016/j.enggeo.2008.11.009.

Yin, Z. Y., Zhao, J. \& Hicher, P. Y. (2014). A micromechanics-based model for sand-silt mixtures. Int. J. Solids Structs 51, No. 6, 1350-1363, https://doi.org/10.1016/j.ijsolstr.2013.12.027.

Zhou, W., Xu, K., Ma, G., Yang, L. \& Chang, X. (2016). Effects of particle size ratio on the macro- and microscopic behaviors of binary mixtures at the maximum packing efficiency state. Granul. Matter 18, No. 4, article 81, https://doi.org/10.1007/ s10035-016-0678-1.

Zhu, Y., Nie, Z., Gong, J., Zou, J., Zhao, L. \& Li, L. (2020). An analysis of the effects of the size ratio and fines content on the shear behaviors of binary mixtures using DEM. Comput. Geotech. 118, No. 4, 103353, https://doi.org/10.1016/j.compgeo. 2019.103353

Zlatović, S. \& Ishihara, K. (1995). On the influence of nonplastic fines on residual strength. In Earthquake geotechnical engineering (ed. K. Ishihara), pp. 239-244. Rotterdam, the Netherlands: Balkema.

Zuo, L. \& Baudet, B. A. (2015). Determination of the transitional fines content of sand-non plastic fines mixtures. Soils Found. 55, No. 1, 213-219, https://doi.org/10.1016/j.sandf.2014.12.017. 